\title{
Análise da degradação da caatinga no núcleo de desertificação do Seridó (RN/PB)
}

\author{
Thomaz C. e C. da Costa ${ }^{1}$, Maria A. J. de Oliveira ${ }^{2}$, Luciano J. de 0. Accioly ${ }^{3} \&$ Flávio H. B. B. da Silva ${ }^{3}$
}

\section{RESUMO}

A condição de aridez associada à pressão antrópica resulta em áreas de degradação extrema, conhecidas como núcleos de desertificação. No núcleo do Seridó a antropização é caracterizada por queimadas, cultivo do algodão no passado, pastoreio e exploração de lenha, que alteraram a composição florística ea estrutura da vegetação potencial. Com este estudo se objetivou identificar níveis de degradação na caatinga arbóreo-arbustiva do Seridó, por meio de técnicas multivariadas que envolveram variáveis do ambiente físico, da florística, fitofisionomia e diversidade da vegetação. 0 inventário florístico e fitossociológico foi realizado em 16 fragmentos, pelo método Ponto-Q uadrante, com a inclusão de plantas com diâmetros no nível do solo 1 $\mathrm{cm}$ e altura $\geq 1 \mathrm{~m}$, totalizando 3472 indivíduos, que foram identificados em 15 famílias, 24 gêneros e 31 espécies. As famílias Euphorbiaceae, M imosaceae, Apocynaceae e Caesal pinaceae apresentaram maiores VI, assim como as espécies Croton hemiargyreus, Aspidosperma pyrifolium, Mimosa hostilis, Caesalpinia pyramidalis e Jatropha mollissima. $0 \mathrm{~s}$ resultados mostraram que a degradação dos fragmentos está associada às condições ambientais mais favoráveis, o que indica causa antrópica da degradação.

Palavras-chave: florística, fitossociologia, biodiversidade, análise multivariada

\section{Analysis of degradation of 'Caatinga' in the desertification nucleus of Seridó - Brazil}

\begin{abstract}
The anthropic pressure on the Brazilian semi-arid biome of 'caatinga' leads to extreme degradation areas known as desertification nucleus. In the desertification nucleus of Seridó the anthropisms are characterized by burning of 'caatinga' vegetation, cotton crop in the past, pasture and native vegetation exploitation, which altered the floristic composition and the structure of the potential vegetation. The objective of this study was to identify the degree of degradation of 'caatinga' vegetation of Seridó by means of multivariate techniques involving the environmental, phytofisionomy, diversity of vegetation. The floristic and phytossociologic inventory were carried out in 16 , by square - point method with the inclusion of plants with stem diameter at ground level $\geq 1 \mathrm{~cm}$ and height $\geq 1 \mathrm{~m}$, totalizing 3472 plants, which were identified in 15 families and 31 species. The Euphorbiaceae, M imosaceae, Apocynaceae and Caesal pinaceae family and Croton hemiargyreus, Aspidosperma pyrifolium, Mimosa hostilis, Caesal pinia pyramidalis, Jatropha mollissima species occurred higher VI. The results showed that degradation of 'caatinga' is associated with more favorable environmental conditions, that evidence antropic causes of degradation.
\end{abstract}

Key words: floristic, phytossociology, biodiversity, multivariate analysis

${ }^{1}$ Embrapa Solos. CEP 24000-001, Rio de Janeiro, RJ. Fone (21) 2274-4999. E-mail: thomaz@cnpms.embrapa.br

2 Instituto de Biologia/U FBA. CEP 40170-270, Salvador, BA. Fone (71) 3263-6531. E-mail: cidinhaba@hotmail.com

3 Embrapa Solos/UEP, Recife. CEP 52020-240, Recife, PE. Fone (81) 3325-5988, Ramal(s): 218/229. E-mail(s): luciano@uep.cnps.embrapa.br; flavio@uep.cnps.embrapa.br 


\section{INTRODUÇÃO}

A desertificação é definida como a degradação dos solos, dos recursos hídricos e da biodiversidade, nas zonas áridas, semiáridas e subúmidas secas, resultantes de fatores climáticos e atividades humanas (United Nations, 1994).

No Brasil as áreas suscetíveis à desertificação alcançam $980.711 \mathrm{~km}^{2}$, distribuídos em oito estados do Nordeste e no norte do Estado de Minas Gerais. Na região do Seridó a área afetada é de aproximadamente $2.341 \mathrm{~km}^{2}$ e a pressão antrópica, que contribuiu para este processo, foi relativa às queimadas, ao cultivo do algodão, pastoreio e ao desmatamento, principais responsáveis pela perda da diversidade florística (Luetzelburg, 1923; Andrade-Lima, 1981).

No semiárido nordestino a variação climática, do solo e os tipos de relevo, formam paisagens, como os vales úmidos, as chapadas sedimentares e as amplas superfícies pediplainadas que condicionam a estrutura e a diversidade da vegetação (Santana \& Souto, 2006; Trovão et al., 2007), de forma que formações caducifólias e espinhosas se estabeleceram na depressão e formações florestais ocuparam as serras e chapadas (Gomes et al., 2006), mas a evidência da alteração antrópica em fragmentos de caatinga, por meio de históricos e em diferentes escalas e processos, levanta a questão do quanto é difícil identificar a vegetação potencial (Brzeziecki et al., 1993).

Na região semiárida predomina a pecuária extensiva, com o consumo do pasto nativo efêmero na época das chuvas e, na seca, o rebanho sobrevive de folhas e frutos das espécies forrageiras arbustivas e arbóreas (Moreira et al., 2006). O manejo rudimentar do gado, as áreas abandonadas de antigos campos de algodão, a extração de lenha para atender às demandas de olarias e cerâmicas, e a mineração, degradaram a caatinga em diferentes intensidades (IBAMA, 1993; Sampaio et al., 1998; Matalho, 2001), e algumas comunidades já percebem os impactos da degradação, com o desaparecimento de espécies da flora e da fauna (Alves et al., 2009).

Constatou-se, na região do Seridó, grande variação da biomassa arbórea-arbustiva (Costa et al., 2002), relacionada às condições topográficas e ao uso da terra. Sucessivos cortes para uso de lenha, ou supressão para uso agrícola, ou pastoreiro, e posteriormente a regeneração após abandono, resultaram na quebra do equilíbrio entre espécies tardias, intermediárias e pioneiras, na exposição do solo e perda do banco de sementes. A degradação é, ainda, proporcional ao tipo de alteração do solo, à intensidade e tempo de uso.

A caatinga do Seridó é uma vegetação hiperxerófila, com aspecto arbóreo-arbustivo esparso e se fixa em solos rasos, pedregosos e erodíveis. O estrato herbáceo é composto principalmente por Aristida setifolia (capim panasco) e as cactáceas estão representadas por vários táxons (Luetzelburg, 1923; Andrade-Lima, 1981), ocorrendo também variação fisionômica quanto ao porte, biomassa e densidade de plantas (IBAMA, 1993; Costa et al., 2002).

Philipp Von Luetzelburg descreveu a Caatinga do Seridó como uma subespécie da caatinga, afirmando que sua origem não é endêmica e sim, criada posteriormente pela influência do homem; deram-lhe origem as grandes e repetidas queima- das, das quais lançavam mão os primeiros colonizadores, como meio eficaz de defesa contra os contínuos ataques do gentio, e também para forçarem uma passagem através da densíssima vegetação da caatinga (Luetzelburg, 1923). O registro mais antigo de colonização data de 300 anos, idade de um muro de pedra, arquitetura típica da região (Seridó, 2001).

Outros autores caracterizaram a caatinga do Seridó como distinta das outras caatingas, pelo porte e pela densidade de plantas (Andrade-Lima, 1981; Amorim et al., 2005). A Estação Ecológica do Seridó, no município de Serra Negra do Norte, $\mathrm{RN}$, transformada em unidade de conservação em 1982, que era anteriormente uma fazenda, é utilizada para caracterização da flora potencial do Seridó (Camacho, 2001; Amorim et al., 2005; Santana \& Souto, 2006).

Por meio de inventários fitossociológicos realizados na Caatinga, com a finalidade de se estabelecer relações entre solo e planta (Santos, 1987; Silva, 1991; Rodal, 1992, Camacho, 2001), de conhecimento florístico e fitossociológico (Araújo et al., 1995; Rodal et al., 1998; Farias \& Castro, 2004; Costa et al., 2007; Barbosa et al., 2007), de comparação entre levantamentos florísticos, segundo condições edafoclimáticas (Rodal, 1992, Alcoforado Filho et al., 2003; Rocha et al., 2004; Trovão et al., 2004; Reis et al., 2006; Santos et al., 2007), e de inventariar as caatingas arbustivo-arbóreas, de acordo com diretrizes da SUDENE (Tavares et al., 1969a, 1969b, 1970, 1974a, 1974b, 1975) identificaram-se locais com menor diversidade de espécies arbóreo-arbustivas da caatinga, que incluem a região do Seridó e da microrregião salineira no Rio Grande do Norte, e o Vale do Cariri na Paraíba, onde na maioria dos levantamentos ocorreram menos de 10 espécies.

Com esses dados se relacionaram parâmetros climáticos com o número de espécies arbóreo-arbustivo da caatinga, verificando-se tendência no aumento do número de espécies com o aumento da razão entre precipitação anual (P) e temperatura média anual $(\mathrm{T})$, ocorrendo dispersão apenas para o lado esquerdo da linha de tendência, o que significa dizer que, fixando-se a razão climática $(\mathrm{P} / \mathrm{T})$ e a região, o número de espécies reduz, dependendo do fragmento inventariado (Costa et al., 2003). O Seridó-RN/PB é uma das regiões com esta variabilidade, com a hipótese de redução da diversidade florística dos fragmentos pela ação antrópica.

Uma metodologia para testar tal hipótese, foi abordada neste trabalho, com o objetivo de identificar níveis de degradação na caatinga arbóreo-arbustiva do Seridó, por meio de técnicas multivariadas que envolveram variáveis do ambiente físico (edáfica e topográficas), da florística e de parâmetros fitossociológicos, de cobertura e diversidade da vegetação.

\section{MATERIAL E MÉTODOS}

Uma área de $750 \mathrm{~km}^{2}(25 \times 30 \mathrm{~km})$ foi selecionada, correspondendo a $32 \%$ do núcleo de desertificação do Seridó, localizada na região centro sul do Estado do Rio Grande do Norte e centro-norte da Paraíba (Figura 1).

A precipitação anual varia de 350 a $800 \mathrm{~mm}$, com média histórica de $600 \mathrm{~mm}$ e concentração de chuvas entre janeiro e abril. O período seco vai de julho a dezembro. A temperatura 


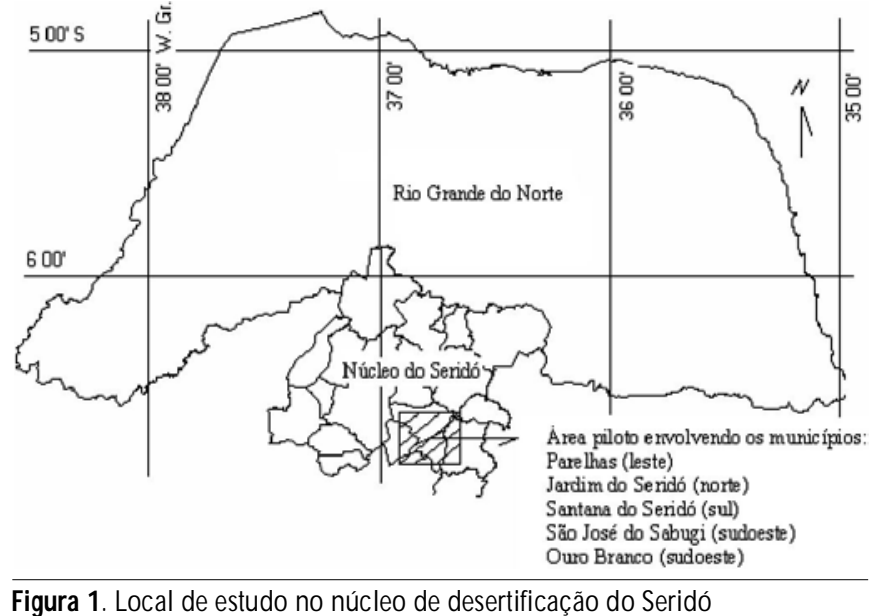

média anual é de $30,7^{\circ} \mathrm{C}$, com a máxima média ocorrendo em outubro $\left(31^{\circ} \mathrm{C}\right)$ e a mínima média em fevereiro $(29,3$ ${ }^{\circ} \mathrm{C}$ ). A umidade relativa média é de $63 \%$, sendo abril o mês mais úmido e novembro o mais seco. A insolação média anual é de 2981 horas, que representa 8,3 h diárias de sol e o período de maior insolação é de setembro a dezembro. Os valores de evaporação são aproximadamente cinco vezes ou mais que os de precipitação (Silva et al., 2001; Amorim et al., 2005).

Selecionaram-se 16 fragmentos de caatinga (Figura 2) e, para o inventário fitossociológico, adotou-se o método do Ponto Quadrante (Cottam \& Curtis, 1956; Martins, 1993). Os primeiros fragmentos $(1,2,3)$ foram amostrados por dois transectos de $500 \mathrm{~m}$, os fragmentos 4, 5, 6 e 7 o foram por um transecto de $500 \mathrm{~m}$ e, pela avaliação da curva "espécie x tamanho do transecto", estabeleceu-se um transecto de $400 \mathrm{~m}$ para os demais fragmentos. Em cada transecto foram estabelecidos pontos equidistantes $10 \mathrm{~m}$ e em cada ponto foram amostrados quatro indivíduos arbustivos ou arbóreos, mais

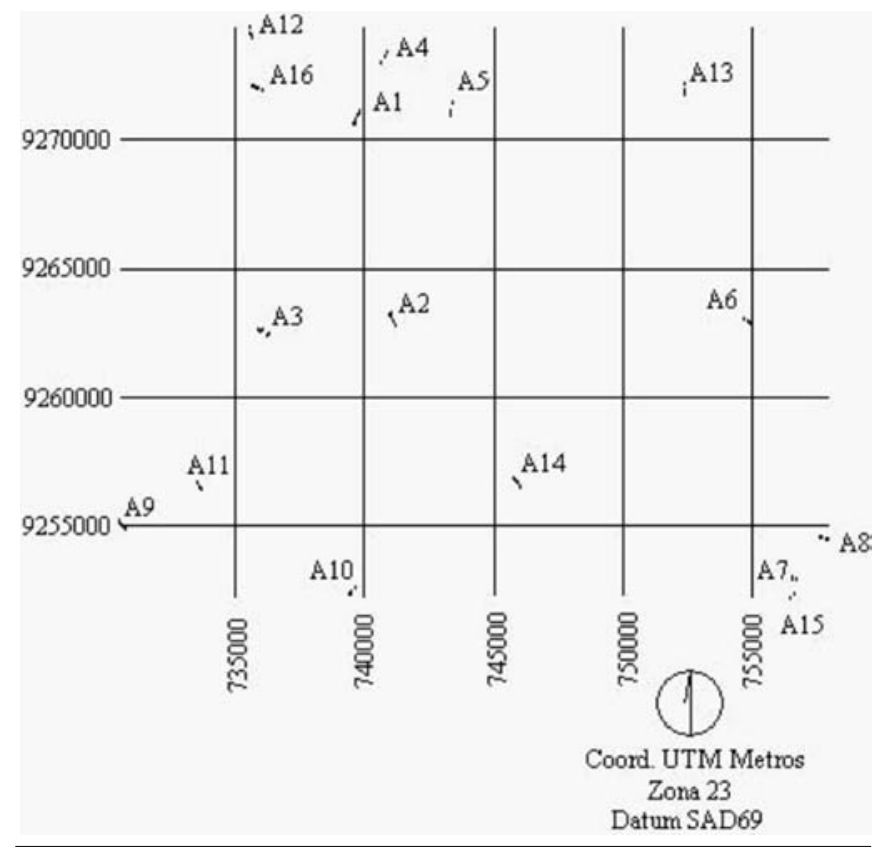

Figura 2. Localização dos transectos em 16 áreas inventariadas próximos, um por quadrante, com diâmetro basal (nível do solo) $\geq 1 \mathrm{~cm}$ e altura $\geq 1 \mathrm{~m}$. Para cada indivíduo foram mensuradas: a distância da planta até o ponto, a circunferência da base de cada perfilho e a altura total.

A coleta do material botânico foi realizada para cada fragmento inventariado, sendo este material etiquetado e prensado e posteriormente identificado por um especialista pela comparação com typus ou por chaves taxionômicas. As exsicatas estão depositadas no Herbário do Instituto de Pesquisa Agronômica (IPA) de Pernambuco.

Obteve-se o levantamento de solos em Silva et al. (2001). As classes de solo foram categorizadas por consulta com especialistas, referentes ao favorecimento do tipo de solo para o porte e a diversidade florística dos fragmentos de caatinga (Costa et. al., 2003). Obtiveram-se a altimetria, a declividade e o aspecto, utilizando-se o Idrisi ${ }^{\circledR}$ a partir de curvas de nível de 40 em $40 \mathrm{~m}$, digitalizadas da carta topográfica do IBGE na escala 1:100.000.

Para os fragmentos se obtiveram a densidade (número de indivíduos $\left.\mathrm{m}^{-2}\right)$, a área basal $\left(\mathrm{m}^{2} \mathrm{ha}^{-1}\right)$, a altura média $(\mathrm{m})$, o desvio-padrão da altura e o índice de área foliar em ambientes semiáridos (IAF) (White et al., 2000; Costa et al., 2002). Os parâmetros fitossociológicos de densidade, dominância, frequência e o valor de importância (VI) foram obtidos por família e espécie, conforme metodologia apresentada em Cottam \& Curtis (1956) e, para a diversidade florística, foram calculados os índices de Shannon (Krebs, 1989), de dominância de Simpson (Simpson, 1949) e de Jaccard (Magurran, 1991).

As atividades antrópicas foram levantadas em relatórios do IBAMA (1993) e de informações colhidas na localidade.

As análises de agrupamento para os fragmentos foram aplicadas considerando-se variáveis de ambiente, de cobertura e de diversidade, utilizando-se distância euclidiana de ligação simples (Johnson \& Wichern, 1988), com a finalidade de se identificar grupos de fragmentos similares, pelos tipos de variáveis. Aplicou-se a análise de correlação canônica (Johnson \& Wichern, 1988) para investigar a relação das variáveis de ambiente (Alt, Asp, Decl, S) com as variáveis de cobertura e diversidade (DT, B, H, H_dp, IAF, NE, Hdiver, C), com a amostra de 16 fragmentos, similar à aplicação em Manly (1994).

A análise de correspondência (Johnson \& Wichern, 1988; Manly, 1994), foi aplicada para identificar a associação entre espécies e fragmentos.

\section{RESULTADOS E DISCUSSÃO}

Nos 16 fragmentos foram amostrados 3472 indivíduos, identificadas 15 famílias, 24 gêneros e 31 espécies (Tabela 1). Pela curva cumulativa do número de espécies por pontos (Figura 3), na maioria dos fragmentos ocorreu a estabilização do número de espécies, em torno de 40 pontos (400 $\mathrm{m}$ de transecto). O número de espécies identificadas por fragmento variou de 4 a 18.

As famílias com maior VI, foram: Euphorbiaceae $(111,6)$, Mimosaceae $(57,29)$, Apocynaceae $(56,85)$ e Caesalpiniaceae $(51,24)$, representando $93 \%$ dos indivíduos; na hierarquia de 
Tabela 1. Fragmentos amostrados, classes de densidade dos fragmentos (V), altitude (Alt.(m)), declividade( $(0)$, Dec, Aspecto, ( $\left.{ }^{\circ}\right)$, Asp, classe de solo (CS), nota do Solo (S), densidade de árvores, ind. $\mathrm{m}^{-2}$, (DT), área basal, $\mathrm{m}^{2} / \mathrm{ha}$, (B), altura média, $\mathrm{m},(\mathrm{H})$, desvio padrão da altura (H_DP), índice de área foliar (IAF), número de espécies (NE), índice de diversidade de Shannon-W eaver (H'), índice de dominância de Simpson (C)

\begin{tabular}{|c|c|c|c|c|c|c|c|c|c|c|c|c|c|}
\hline Fragmento & $\mathbf{V}^{* *}$ & Alt (m) & Dec & Asp & CS*** & S* & DT & B & H & H_DP & IAF & $\mathrm{H}^{\prime}$ & C \\
\hline 1. Canto Alegre & $\mathrm{Ta}$ & 240 & 0 & -1 & RLCo & 5 & 0,1708 & 13,64 & 3,31 & 1,1153 & 1,42 & 1,32 & 0,34 \\
\hline 2. Humaitá & $\mathrm{Tp}$ & 250 & 0 & -1 & TCoe & 5 & 0,0865 & 3,14 & 2,33 & 0,8033 & 0,84 & 1,57 & 0,29 \\
\hline 3. São Roque & $\mathrm{Tp}$ & 250 & 0 & -1 & TCoe & 5 & 0,0424 & 3,59 & 2,09 & 0,9701 & 0,27 & 1,43 & 0,28 \\
\hline 4. Curucuru & $\mathrm{Tp}$ & 246 & 0 & -1 & TCoe & 5 & 0,1291 & 5,81 & 1,99 & 0,7064 & 0,57 & 1,57 & 0,24 \\
\hline 5. São Gonçalo & $\mathrm{Tp}$ & 250 & 0 & -1 & RUq & 5 & 0,1167 & 4,23 & 2,06 & 0,7621 & 0,4 & 1,74 & 0,21 \\
\hline 6. Sussuarana & $\mathrm{Tp}$ & 250 & 0 & -1 & SNo & 4 & 0,0364 & 2,12 & 2,39 & 1,0651 & 0,52 & 2,03 & 0,17 \\
\hline 7. Quintos & $\mathrm{Td}$ & 419 & 11,1 & 308 & RLe/RLd & 5 & 0,3900 & 11,02 & 2,61 & 1,0937 & 2,24 & 2,28 & 0,14 \\
\hline 8. Várzea Barro & $\mathrm{Td}$ & 473 & 15,9 & 285 & SNo & 5 & 0,4218 & 14,41 & 2,86 & 1,3282 & 2,79 & 1,84 & 0,23 \\
\hline 9. Sítio Açude & $\mathrm{Ta}$ & 270 & 1,2 & 311 & SNo & 4 & 0,3047 & 13,51 & 3,07 & 1,0824 & 1,12 & 1,53 & 0,37 \\
\hline 10. Sítio Riacho & $\mathrm{Ta}$ & 292 & 0 & -1 & SNo & 4 & 0,1131 & 5,41 & 2,80 & 0,8517 & 1,05 & 1,81 & 0,21 \\
\hline 11. Carnaubinha & $\mathrm{Ta}$ & 250 & 0,3 & 16 & TCO & 4 & 0,3598 & 13,98 & 3,12 & 0,9945 & 1,15 & 1,21 & 0,44 \\
\hline 12. Umburana & $\mathrm{Tp}$ & 221 & 0 & -1 & SNo & 5 & 0,1029 & 4,86 & 2,22 & 0,7365 & 0,47 & 1,08 & 0,40 \\
\hline 13. Cachoeira & $\mathrm{Ta}$ & 250 & 0 & -1 & $\mathrm{TCO}$ & 4 & 0,4213 & 11,82 & 2,79 & 1,0387 & 2,36 & 1,73 & 0,22 \\
\hline 14. Poço Salgado & $\mathrm{Ta}$ & 297 & 0 & -1 & RLd & 5 & 0,2293 & 9,76 & 3,01 & 1,1191 & 1,1 & 1,81 & 0,25 \\
\hline 15. Quintos de baixo & $\mathrm{Td}$ & 444 & 21,8 & 296 & RLe/RLd & 5 & 0,4218 & 13,68 & 3,40 & 1,4029 & 3,11 & 2,09 & 0,20 \\
\hline 16. Veados & $\mathrm{Tp}$ & 216 & 0 & -1 & RLCo & 5 & 0,0658 & 2,59 & 2,30 & 0,8131 & 0,47 & 1,04 & 0,39 \\
\hline
\end{tabular}

*nota média de favorecimento do solo ao porte e ao vigor da vegetação, pelo julgamento de cinco especialistas (Costa et al., 2003); **Classificação da vegetação (Veloso \& Goes Filho, 1982): Savana Estépica Florestada (Td), Sav. Estép. Arborizada (Ta), Sav. Estép. Parque (Tp), Sav. Estép. Gramíneo-Lenhosa (Tg); ***Legenda: RLCo - Neossolos Litólicos Crômicos Órticos; TCoe - Luvissolos Crômicos Órticos Eutróficos; RUq Neossolos Psamíticos; RLe - Neossolos Litólicos Eutróficos; RLe - Neossolos Litólicos Eutróficos; RLd - Neossolos Litólicos Distróficos; SNo Planossolos Nátricos Órticos; TCo - Luvissolos Crômicos Órticos

VI, a próxima família, Combretaceae, teve apenas 8,45, enquanto as famílias com VI $<1$, foram Fabaceae, Boraginaceae, Capparaceae, Rhamnaceae, Malvaceae e Vebernaceae.

A espécie que se destacou no levantamento com maior VI $(65,65)$, foi o Croton sonderianus Muell.Arg. Marmeleiro, com a maior densidade e frequência (Tabela 1A), com boa distribuição também em outras tipologias de caatinga (Sampaio et al., 1998). A segunda em valor de importância foi Aspidosperma pyrifolium Mart. Pereiro $(54,85)$, que também obteve maior VI no levantamento realizado por Santana \& Souto (2006); a Mimosa hostilis Benth. Jurema preta $(45,73)$ ficou em terceiro lugar seguida da Caesalpinia pyramidalis Tul. Catingueira $(43,76)$, Jatropha mollissima (Pohl.) Baill Pinhão-bravo $(24,36)$, e a Cnidoscolus phyllacanthus Pax E.K. Hoffm.. Faveleira $(17,91)$.

As espécies com VI $<1$ foram: Croton sp. Quebra faca, Anadenanthera macrocarpa (Benth.) Brenan Angico vermelho, Amburana cearensis (Fr. All.) A.C. Smith Imburana de cheiro, Cordia salzmanni D.C. Maria preta, Caesalpinia ferrea Mart. Jucá, Spondias tuberosa Arruda Umbuzeiro, Tabe-

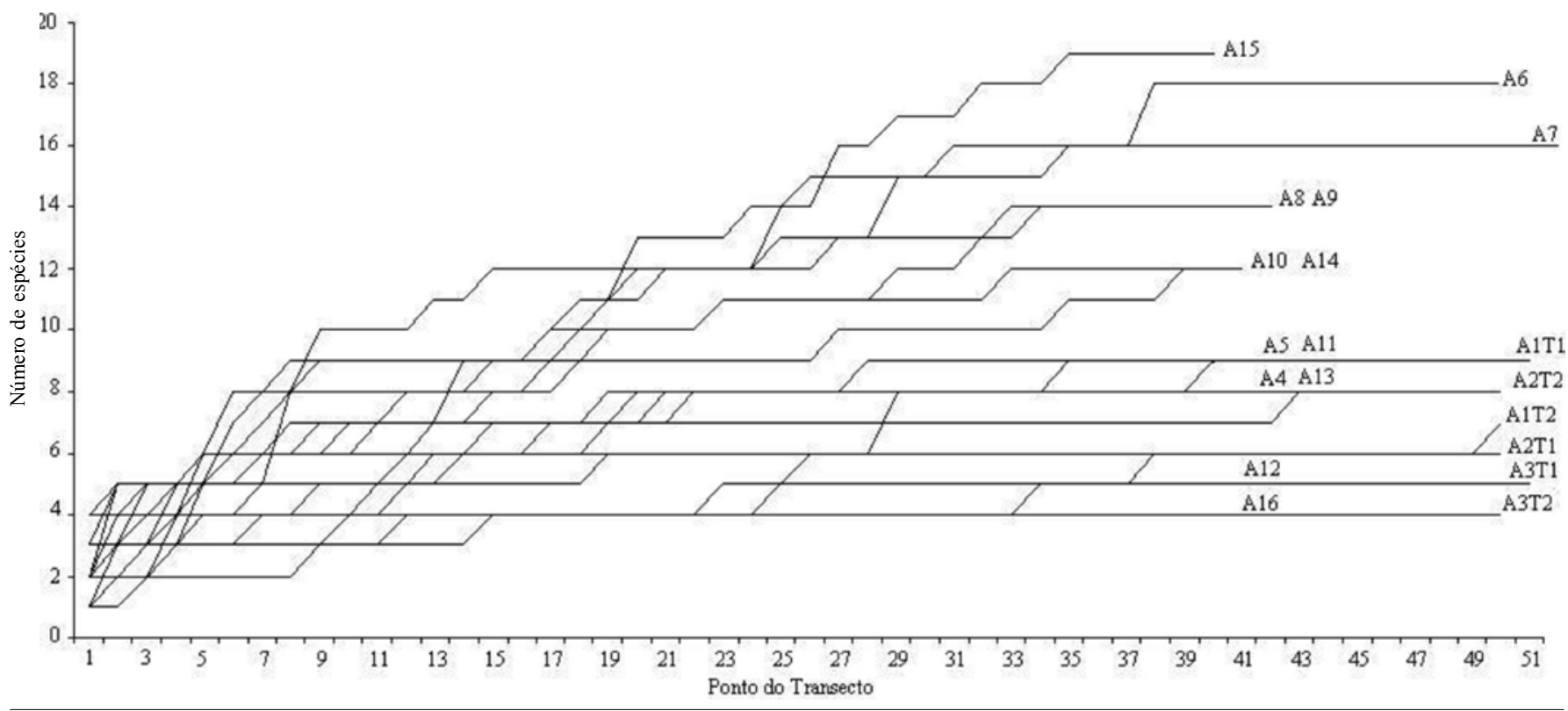

Figura 3. Relação entre número de espécies e pontos do transec to para as 16 áreas amostradas 
Tabela 1A. Relação das espécies presentes nos fragmentos inventariados da caatinga do núcleo de desertificação do Seridó-RN /PB, em ordem decrescente do Índice de Valor de Importância (VI); com Identificador de espécies (Id); Número de indivíduos (Ni); Densidades Absoluta (Di) e Relativa (DR); Frequências Absoluta (fi) e Relativa (FR); e Coberturas Absoluta (Ci) e Relativa (CR)

\begin{tabular}{|c|c|c|c|c|c|c|c|c|c|c|c|c|}
\hline Area & id & Nome científico & Nome comum & Família & $\mathrm{Ni}$ & Di & DR & fi & FR & $\mathrm{Ci}$ & CR & VI \\
\hline \multirow{11}{*}{1} & $p$ & Mimosa hostilis Benth. & J urema preta & Mimosaceae & 127 & 5,37 & 31,44 & 0,32 & 31,76 & 0,07 & 49,38 & 112,57 \\
\hline & $\mathrm{t}$ & Croton hemiargyreus Mull,Arg. & Marmeleiro & Euphorbiaceae & 195 & 8,25 & 48,27 & 0,32 & 32,43 & 0,02 & 15,59 & 96,29 \\
\hline & e & Caesalpinia pyramidalis Tul. & Catingueira & Caesalpinaceae & 44 & 1,86 & 10,89 & 0,16 & 16,22 & 0,03 & 25,52 & 52,63 \\
\hline & $\mathrm{ac}$ & Aspidosperma pyrifolium Mart. & Pereiro & Apocynaceae & 12 & 0,51 & 2,97 & 0,06 & 6,08 & 0,01 & 5,01 & 14,06 \\
\hline & $\mathrm{ad}$ & J atropha mollissima (Pohl.) Baill & Pinhão bravo & Euphorbiaceae & 17 & 0,72 & 4,21 & 0,08 & 8,11 & 0 & 1,65 & 13,97 \\
\hline & ah & $\begin{array}{l}\text { Pilosocereus gounellei (A. Weber ex K. } \\
\text { Schum.) Byles \& Rowley }\end{array}$ & Xique xique & Cactaceae & 4 & 0,17 & 0,99 & 0,03 & 2,7 & 0 & 1,43 & 5,12 \\
\hline & $\mathrm{h}$ & Cnidoscolus phyllacanthus Pax E.K. Hoffm. & Faveleira & Euphorbiaceae & 1 & 0,04 & 0,25 & 0,01 & 0,68 & 0 & 0,74 & 1,66 \\
\hline & k & Amburana cearensis (Fr. All.) A.C. Smith & Imburana de cheiro & Fabaceae & 1 & 0,04 & 0,25 & 0,01 & 0,68 & 0 & 0,44 & 1,36 \\
\hline & $\mathrm{ag}$ & Croton campestris A. St. Hil. & Velame & Euphorbiaceae & 2 & 0,08 & 0,5 & 0,01 & 0,68 & 0 & 0,15 & 1,32 \\
\hline & v & Combretum leprosum Mart. & Mofumbo & Combretaceae & 1 & 0,04 & 0,25 & 0,01 & 0,68 & 0 & 0,08 & 1,01 \\
\hline & & $\begin{array}{r}\text { Total } \\
\end{array}$ & & 10 & 404 & 17,08 & 100 & 1 & 100 & 0,14 & 100 & 300 \\
\hline \multirow{10}{*}{2} & $\mathrm{t}$ & Croton hemiargyreus Mull.Arg. & Marmeleiro & Euphorbiaceae & 198 & 4,28 & 49,5 & 0,27 & 26,52 & 0,01 & 21,39 & 97,41 \\
\hline & ac & Aspidosperma pyrifolium Mart. & Pereiro & Apocynaceae & 54 & 1,17 & 13,5 & 0,19 & 18,78 & 0,01 & 34,08 & 66,36 \\
\hline & e & Caesalpinia pyramidalis Tul. & Catingueira & Leguminosae & 42 & 0,91 & 10,5 & 0,15 & 14,92 & 0 & 10,83 & 36,25 \\
\hline & p & Mimosa hostilis Benth. & J urema preta & Mimosaceae & 30 & 0,65 & 7,5 & 0,13 & 12,71 & 0 & 14,68 & 34,89 \\
\hline & v & Combretum leprosum Mart. & Mofumbo & Combretaceae & 35 & 0,76 & 8,75 & 0,11 & 11,05 & 0 & 7,34 & 27,14 \\
\hline & $\mathrm{ad}$ & J atropha mollissima (Pohl.) Baill & Pinhão bravo & Euphorbiaceae & 30 & 0,65 & 7,5 & 0,1 & 9,94 & 0 & 7,48 & 24,93 \\
\hline & $\mathrm{h}$ & Cnidoscolus phyllacanthus Pax E.K. Hoffm. & Faveleira & Euphorbiaceae & 9 & 0,19 & 2,25 & 0,05 & 4,97 & 0 & 3,83 & 11,05 \\
\hline & ah & $\begin{array}{l}\text { Pilosocereus gounellei (A. Weber ex K. } \\
\text { Schum.) Byles \& Rowley }\end{array}$ & Xique xique & Cactaceae & 1 & 0,02 & 0,25 & 0,01 & 0,55 & 0 & 0,32 & 1,12 \\
\hline & ae & Croton sp. & Quebra faca & Euphorbiaceae & 1 & 0,02 & 0,25 & 0,01 & 0,55 & 0 & 0,05 & 0,86 \\
\hline & & Total & & 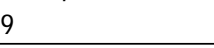 & 400 & 8,66 & 100 & 1 & 100 & 0,03 & 100 & 300 \\
\hline \multirow{7}{*}{3} & $\mathrm{ac}$ & Aspidosperma pyrifolium Mart. & Pereiro & Apocynaceae & 175 & 1,84 & 43,32 & 0,31 & 30,86 & 0,02 & 53,05 & 127,23 \\
\hline & $\mathrm{h}$ & Cnidoscolus phyllacanthus Pax E.K. Hoffm. & Faveleira & Euphorbiaceae & 68 & 0,71 & 16,83 & 0,21 & 20,99 & 0,01 & 34,96 & 72,77 \\
\hline & $\mathrm{ad}$ & J atropha mollissima (Pohl.) Baill & Pinhão bravo & Euphorbiaceae & 94 & 0,99 & 23,27 & 0,24 & 24,07 & 0 & 10,02 & 57,36 \\
\hline & $\mathrm{t}$ & Cróton hemiargyreus Mull.Arg. & Marmeleiro & Euphorbiaceae & 41 & 0,43 & 10,15 & 0,16 & 16,05 & 0 & 1,82 & 28,02 \\
\hline & e & Caesalpinia pyramidalis Tul. & Catingueira & Leguminosae & 1 & 0,01 & 0,25 & 0,01 & 0,62 & 0 & 0,16 & 1,02 \\
\hline & $z$ & não determinada & não determinada & Não determinada & 25 & 0,26 & 6,19 & 0,07 & 7,41 & 0 & 0 & 13,6 \\
\hline & & Total & & 5 & 404 & 4,24 & 100 & 1 & 100 & 0,04 & 100 & 300 \\
\hline \multirow{9}{*}{4} & e & Caesalpinia pyramidalis Tul. & Catingueira & Leguminosae & 64 & 4,13 & 32 & 0,3 & 29,85 & 0,03 & 45,7 & 107,55 \\
\hline & $t$ & Croton hemiargyreus Mull.Arg. & Marmeleiro & Euphorbiaceae & 64 & 4,13 & 32 & 0,26 & 26,12 & 0,01 & 13,9 & 72,02 \\
\hline & $\mathrm{ac}$ & Aspidosperma pyrifolium Mart. & Pereiro & Apocynaceae & 34 & 2,19 & 17 & 0,18 & 17,91 & 0,01 & 16,25 & 51,16 \\
\hline & $\mathrm{ad}$ & J atropha mollissima (Pohl.) Baill & Pinhão bravo & Euphorbiaceae & 21 & 1,36 & 10,5 & 0,15 & 14,93 & 0 & 8,31 & 33,74 \\
\hline & $\mathrm{h}$ & Cnidoscolus phyllacanthus Pax E.K. Hoffm. & Faveleira & Euphorbiaceae & 11 & 0,71 & 5,5 & 0,07 & 6,72 & 0,01 & 14,07 & 26,28 \\
\hline & ah & $\begin{array}{l}\text { Pilosocereus gounellei (A. Weber ex K. } \\
\text { Schum.) Byles \& Rowley }\end{array}$ & Xique xique & Cactaceae & 2 & 0,13 & 1 & 0,01 & 1,49 & 0 & 1,56 & 4,05 \\
\hline & $\mathrm{ag}$ & Croton campestris A. St. Hil. & Velame & Euphorbiaceae & 3 & 0,19 & 1,5 & 0,02 & 2,24 & 0 & 0,09 & 3,82 \\
\hline & i & Capparis flexuosa L. & Feijão bravo & Capparaceae & 1 & 0,06 & 0,5 & 0,01 & 0,75 & 0 & 0,13 & 1,37 \\
\hline & & Total & & 8 & 200 & 12,91 & 100 & 1 & 100 & 0,06 & 100 & 300 \\
\hline \multirow{10}{*}{5} & $\mathrm{e}$ & Caesalpinia pyramidalis Tul. & Catingueira & Leguminosae & 69 & 4,03 & 34,5 & 0,3 & 29,6 & 0,02 & 46,8 & 110,9 \\
\hline & $\mathrm{ad}$ & J atropha mollissima (Pohl.) Baill & Pinhão bravo & Euphorbiaceae & 39 & 2,28 & 19,5 & 0,23 & 23,2 & 0,01 & 13,54 & 56,24 \\
\hline & $\mathrm{t}$ & Croton hemiargyreus Mull.Arg. & Marmeleiro & Euphorbiaceae & 41 & 2,39 & 20,5 & 0,18 & 17,6 & 0 & 3,99 & 42,09 \\
\hline & $\mathrm{ac}$ & Aspidosperma pyrifolium Mart. & Pereiro & Apocynaceae & 21 & 1,23 & 10,5 & 0,1 & 10,4 & 0 & 10,57 & 31,47 \\
\hline & $\mathrm{h}$ & Cnidoscolus phyllacanthus Pax E.K. Hoffm. & Faveleira & Euphorbiaceae & 5 & 0,29 & 2,5 & 0,04 & 4 & 0,01 & 15,17 & 21,67 \\
\hline & $\mathrm{p}$ & Mimosa hostilis Benth. & J urema preta & Mimosaceae & 17 & 0,99 & 8,5 & 0,1 & 9,6 & 0 & 2,89 & 20,99 \\
\hline & ah & $\begin{array}{l}\text { Pilosocereus gounellei (A. Weber ex K. } \\
\text { Schum.) Byles \& Rowley }\end{array}$ & Xique xique & Cactaceae & 4 & 0,23 & 2 & 0,02 & 2,4 & 0 & 3,7 & 8,1 \\
\hline & j & Commiphora leptophloeos (Mart) J .B. Gillett & Imburana & Burceraceae & 3 & 0,18 & 1,5 & 0,02 & 2,4 & 0 & 2,86 & 6,76 \\
\hline & v & Combretum leprosum Mart. & Mofumbo & Combretaceae & 1 & 0,06 & 0,5 & 0,01 & 0,8 & 0 & 0,48 & 1,78 \\
\hline & & Total & & 9 & 200 & 11,68 & 100 & 1 & 100 & 0,04 & 100 & 300 \\
\hline \multirow{6}{*}{6} & e & Caesalpinia pyramidalis Tul. & Catingueira & Leguminosae & 44 & 0,77 & 21,15 & 0,22 & 21,97 & 0,01 & 26 & 69,12 \\
\hline & $\mathrm{t}$ & Croton hemiargyreus Mull.Arg. & Marmeleiro & Euphorbiaceae & 58 & 1,02 & 27,88 & 0,19 & 18,94 & 0 & 10,62 & 57,44 \\
\hline & v & Combretum leprosum Mart. & Mofumbo & Combretaceae & 29 & 0,51 & 13,94 & 0,14 & 14,39 & 0 & 20,5 & 48,83 \\
\hline & $\mathrm{ad}$ & J atropha mollissima (Pohl.) Baill & Pinhão bravo & Euphorbiaceae & 34 & 0,6 & 16,35 & 0,16 & 15,91 & 0 & 7,21 & 39,46 \\
\hline & $\mathrm{h}$ & Cnidoscolus phyllacanthus Pax E.K. Hoffm. & Faveleira & Euphorbiaceae & 8 & 0,14 & 3,85 & 0,06 & 6,06 & 0 & 16,27 & 26,18 \\
\hline & j & Commiphora leptophloeos (Mart) J .B. Gillett & Imburana & Burceraceae & 6 & 0,11 & 2,88 & 0,05 & 4,55 & 0 & 8,66 & 16,09 \\
\hline
\end{tabular}


Continuação...

\begin{tabular}{|c|c|c|c|c|c|c|c|c|c|c|c|c|}
\hline Area & id & Nome científico & Nome comum & Família & $\mathrm{Ni}$ & $\mathrm{Di}$ & DR & fi & FR & $\mathrm{Ci}$ & CR & VI \\
\hline \multirow{11}{*}{6} & $\mathrm{p}$ & Mimosa hostilis Benth. & J urema preta & Mimosaceae & 8 & 0,14 & 3,85 & 0,05 & 5,3 & 0 & 6 & 15,15 \\
\hline & ac & Aspidosperma pyrifolium Mart. & Pereiro & Apocynaceae & 8 & 0,14 & 3,85 & 0,04 & 3,79 & 0 & 2,4 & 10,04 \\
\hline & $f$ & Tabebuia caraíba & Caubeira & Bignoniaceae & 2 & 0,04 & 0,96 & 0,02 & 1,52 & 0 & 0,76 & 3,23 \\
\hline & $\mathrm{x}$ & Bauhinia cheilantha (Bong.) Steud. & Mororo & Caesalpinaceae & 2 & 0,04 & 0,96 & 0,02 & 1,52 & 0 & 0,21 & 2,69 \\
\hline & $\mathrm{ag}$ & Croton campestris A. St. Hil. & Velame & Euphorbiaceae & 1 & 0,02 & 0,48 & 0,01 & 0,76 & 0 & 0,55 & 1,79 \\
\hline & $a b$ & Allamanda blanchetii A.DC. & Pente de macaco & Apocynaceae & 1 & 0,02 & 0,48 & 0,01 & 0,76 & 0 & 0,44 & 1,68 \\
\hline & $\mathrm{n}$ & Piptadenia stipulacea (Benth.) Ducke & Jurema branca & Mimosaceae & 1 & 0,02 & 0,48 & 0,01 & 0,76 & 0 & 0,32 & 1,56 \\
\hline & $q$ & Gaya aurea St. Hil. & Malva & Malvaceae & 1 & 0,02 & 0,48 & 0,01 & 0,76 & 0 & 0,03 & 1,27 \\
\hline & g & Lantana camara L. & Chumbinho & Verbenaceae & 1 & 0,02 & 0,48 & 0,01 & 0,76 & 0 & 0,02 & 1,25 \\
\hline & z & não determinada & não determinada & não determinada & 4 & 0,07 & 1,92 & 0,02 & 2,27 & 0 & 0 & 4,2 \\
\hline & & Total & & & 208 & 3,64 & 100 & 1 & 100 & 0,02 & 100 & 300 \\
\hline \multirow{19}{*}{7} & u & Croton argirophylloides & Marmeleiro branco & Euphorbiaceae & 61 & 11,9 & 30,5 & 0,16 & 16,35 & 0,03 & 24,79 & 71,64 \\
\hline & r & Manihot glaziovii Mull. Arg. & Maniçoba & Euphorbiaceae & 16 & 3,12 & 8 & 0,13 & 12,5 & 0,02 & 14,16 & 34,66 \\
\hline & $p$ & Mimosa hostilis Benth. & J urema preta & Mimosaceae & 24 & 4,68 & 12 & 0,08 & 7,69 & 0,02 & 14,37 & 34,06 \\
\hline & $x$ & Bauhinia cheilantha (Bong.) Steud. & Mororo & Caesalpinaceae & 19 & 3,71 & 9,5 & 0,11 & 10,58 & 0,01 & 8,31 & 28,39 \\
\hline & 0 & Mimosa sp. & Jurema morosa & Mimosaceae & 17 & 3,32 & 8,5 & 0,1 & 9,62 & 0,01 & 8,47 & 26,59 \\
\hline & $\mathrm{ag}$ & Croton campestris A. St. Hil. & Velame & Euphorbiaceae & 21 & 4,1 & 10,5 & 0,08 & 7,69 & 0,01 & 4,67 & 22,86 \\
\hline & j & Commiphora leptophloeos (Mart.) J .B. Gillett & Imburana & Burceraceae & 4 & 0,78 & 2 & 0,04 & 3,85 & 0,01 & 9,55 & 15,39 \\
\hline & $n$ & Piptadenia stipulacea (Benth.) Ducke & J urema branca & Mimosaceae & 9 & 1,76 & 4,5 & 0,07 & 6,73 & 0 & 2,82 & 14,05 \\
\hline & c & Macfadyena róton-cati (L.) Gentry & Bugio & Bignoniaceae & 8 & 1,56 & 4 & 0,07 & 6,73 & 0 & 1,94 & 12,67 \\
\hline & $b$ & Astronium urundeuva Engl. & Aroeira & Anacardiaceae & 3 & 0,59 & 1,5 & 0,03 & 2,88 & 0,01 & 4,72 & 9,11 \\
\hline & $\mathrm{e}$ & Caesalpinia pyramidalis Tul. & Catingueira & Leguminosae & 6 & 1,17 & 3 & 0,04 & 3,85 & 0 & 2,14 & 8,98 \\
\hline & ac & Aspidosperma pyrifolium Mart. & Pereiro & Apocynaceae & 3 & 0,59 & 1,5 & 0,03 & 2,88 & 0 & 0,74 & 5,12 \\
\hline & $\mathrm{t}$ & Cróton hemiargyreus Mull.Arg. & Marmeleiro & Euphorbiaceae & 3 & 0,59 & 1,5 & 0,03 & 2,88 & 0 & 0,48 & 4,87 \\
\hline & a & Anadenanthera macrocarpa (Benth.) Brenan & Angico vermelho & Leguminosae & 2 & 0,39 & 1 & 0,02 & 1,92 & 0 & 0,13 & 3,05 \\
\hline & aa & Caesalpinia róton Mart. Ex Tul. & Pau Ferro & Caesalpinaceae & 1 & 0,2 & 0,5 & 0,01 & 0,96 & 0 & 0,95 & 2,41 \\
\hline & ah & $\begin{array}{l}\text { Pilosocereus gounellei (A. Weber ex K. } \\
\text { Schum.) Byles \& Rowley }\end{array}$ & Xique xique & Cactaceae & 1 & 0,2 & 0,5 & 0,01 & 0,96 & 0 & 0,89 & 2,35 \\
\hline & $\mathrm{ad}$ & J atropha mollissima (Pohl.) Baill & Pinhão bravo & Euphorbiaceae & 1 & 0,2 & 0,5 & 0,01 & 0,96 & 0 & 0,56 & 2,02 \\
\hline & $\mathrm{v}$ & Combretum leprosum Mart. & Mofumbo & Combretaceae & 1 & 0,2 & 0,5 & 0,01 & 0,96 & 0 & 0,31 & 1,77 \\
\hline & & Total & & & 200 & 39,01 & 100 & 1 & 100 & 0,11 & 100 & 300 \\
\hline \multirow{15}{*}{8} & $\mathrm{t}$ & Croton hemiargyreus Mull.Arg. & Marmeleiro & Euphorbiaceae & 71 & 18,72 & 44,38 & 0,33 & 33 & 0,05 & 34,07 & 111,45 \\
\hline & $\mathrm{x}$ & Bauhinia cheilantha (Bong.) Steud. & Mororo & Caesalpinaceae & 33 & 8,7 & 20,63 & 0,24 & 24 & 0,02 & 13,59 & 58,21 \\
\hline & $\mathrm{r}$ & Manihot glaziovii Mull. Arg. & Maniçoba & Euphorbiaceae & 14 & 3,69 & 8,75 & 0,1 & 10 & 0,03 & 21,14 & 39,89 \\
\hline & $\mathrm{e}$ & Caesalpinia pyramidalis Tul. & Catingueira & Leguminosae & 6 & 1,58 & 3,75 & 0,06 & 6 & 0,01 & 6,15 & 15,9 \\
\hline & $\mathrm{ad}$ & J atropha mollissima (Pohl.) Baill & Pinhão bravo & Euphorbiaceae & 9 & 2,37 & 5,63 & 0,05 & 5 & 0 & 3,32 & 13,94 \\
\hline & j & Commiphora leptophloeos (Mart.) J .B. Gillett & Imburana & Burceraceae & 6 & 1,58 & 3,75 & 0,05 & 5 & 0,01 & 4,83 & 13,58 \\
\hline & $p$ & Mimosa hostilis Benth. & J urema preta & Mimosaceae & 3 & 0,79 & 1,88 & 0,03 & 3 & 0,01 & 6,49 & 11,36 \\
\hline & b & Astronium urundeuva Engl. & Aroeira & Anacardiaceae & 5 & 1,32 & 3,13 & 0,05 & 5 & 0 & 2,39 & 10,51 \\
\hline & af & Spondias tuberosa Arruda & Umbuzeiro & Anacardiaceae & 1 & 0,26 & 0,63 & 0,01 & 1 & 0,01 & 5,07 & 6,69 \\
\hline & $\mathrm{ac}$ & Aspidosperma pyrifolium Mart. & Pereiro & Apocynaceae & 3 & 0,79 & 1,88 & 0,02 & 2 & 0 & 1,45 & 5,32 \\
\hline & $\mathrm{v}$ & Combretum leprosum Mart. & Mofumbo & Combretaceae & 2 & 0,53 & 1,25 & 0,02 & 2 & 0 & 0,63 & 3,88 \\
\hline & $\mathrm{n}$ & Piptadenia stipulacea (Benth.) Ducke & J urema branca & Mimosaceae & 2 & 0,53 & 1,25 & 0,02 & 2 & 0 & 0,06 & 3,31 \\
\hline & $\mathrm{ag}$ & Croton campestris A. St. Hil. & Velame & Euphorbiaceae & 2 & 0,53 & 1,25 & 0,01 & 1 & 0 & 0,82 & 3,07 \\
\hline & $z$ & não determinada & não determinada & não determinada & 3 & 0,79 & 1,88 & 0,01 & 1 & 0 & 0 & 2,88 \\
\hline & & Total & & & 160 & 42,19 & 100 & 1 & 100 & 0,14 & 100 & 300 \\
\hline \multirow{15}{*}{9} & $\mathrm{t}$ & Croton hemiargyreus Mull.Arg. & Marmeleiro & Euphorbiaceae & 95 & 17,23 & 56,55 & 0,4 & 40 & 0,03 & 21,38 & 117,93 \\
\hline & $p$ & Mimosa hostilis Benth. & J urema preta & Mimosaceae & 25 & 4,54 & 14,88 & 0,19 & 18,95 & 0,04 & 33,22 & 67,05 \\
\hline & $\mathrm{e}$ & Caesalpinia pyramidalis Tul. & Catingueira & Leguminosae & 16 & 2,9 & 9,52 & 0,13 & 12,63 & 0,03 & 23,93 & 46,08 \\
\hline & ac & Aspidosperma pyrifolium Mart. & Pereiro & Apocynaceae & 6 & 1,09 & 3,57 & 0,06 & 6,32 & 0 & 3,43 & 13,31 \\
\hline & ah & $\begin{array}{l}\text { Pilosocereus gounellei (A. Weber ex K. } \\
\text { Schum.) Byles \& Rowley }\end{array}$ & Xique xique & Cactaceae & 7 & 1,27 & 4,17 & 0,05 & 5,26 & 0 & 1,91 & 11,34 \\
\hline & $\mathrm{h}$ & Cnidoscolus phyllacanthus Pax E.K. Hoffm. & Faveleira & Euphorbiaceae & 2 & 0,36 & 1,19 & 0,02 & 2,11 & 0,01 & 7,74 & 11,03 \\
\hline & $n$ & Piptadenia stipulacea (Benth.) Ducke & Jurema branca & Mimosaceae & 4 & 0,73 & 2,38 & 0,04 & 4,21 & 0 & 1,06 & 7,65 \\
\hline & 0 & Mimosa sp. & J urema morosa & Mimosaceae & 2 & 0,36 & 1,19 & 0,02 & 2,11 & 0 & 2,5 & 5,79 \\
\hline & k & Amburana cearensis (Fr. All.) A.C. Smith & Imburana de cheiro & Fabaceae & 2 & 0,36 & 1,19 & 0,02 & 2,11 & 0 & 1,73 & 5,02 \\
\hline & $\mathrm{m}$ & Caesalpinia ferrea Mart. & Jucá & Leguminosae & 2 & 0,36 & 1,19 & 0,02 & 2,11 & 0 & 1,08 & 4,38 \\
\hline & ad & J atropha mollissima (Pohl.) Baill & Pinhão bravo & Euphorbiaceae & 1 & 0,18 & 0,6 & 0,01 & 1,05 & 0 & 0,86 & 2,51 \\
\hline & $v$ & Combretum leprosum Mart. & Mofumbo & Combretaceae & 1 & 0,18 & 0,6 & 0,01 & 1,05 & 0 & 0,85 & 2,49 \\
\hline & i & Capparis flexuosa L. & Feijão bravo & Capparaceae & 1 & 0,18 & 0,6 & 0,01 & 1,05 & 0 & 0,35 & 1,99 \\
\hline & $z$ & não determinada & não determinada & não determinada & 4 & 0,73 & 2,38 & 0,01 & 1,05 & 0 & 0 & 3,43 \\
\hline & & Total & & & 168 & 30,48 & 100 & 1 & 100 & 0,13 & 100 & 300 \\
\hline
\end{tabular}


Continuação...

\begin{tabular}{|c|c|c|c|c|c|c|c|c|c|c|c|c|}
\hline Area & id & Nome científico & Nome comum & Família & $\mathrm{Ni}$ & $\mathrm{Di}$ & DR & fi & FR & $\mathrm{Ci}$ & CR & VI \\
\hline \multirow{13}{*}{10} & $p$ & Mimosa hostilis Benth. & J urema preta & Mimosaceae & 41 & 2,83 & 25 & 0,24 & 24,32 & 0,02 & 43,13 & 92,45 \\
\hline & $t$ & Croton hemiargyreus Mull.Arg. & Marmeleiro & Euphorbiaceae & 51 & 3,52 & 31,1 & 0,26 & 26,13 & 0 & 8,74 & 65,96 \\
\hline & $\mathrm{ac}$ & Aspidosperma pyrifolium Mart. & Pereiro & Apocynaceae & 33 & 2,28 & 20,12 & 0,17 & 17,12 & 0,01 & 26,94 & 64,18 \\
\hline & e & Caesalpinia pyramidalis Tul. & Catingueira & Leguminosae & 15 & 1,03 & 9,15 & 0,13 & 12,61 & 0 & 4,56 & 26,32 \\
\hline & $\mathrm{ad}$ & J atropha mollissima (Pohl.) Baill & Pinhão bravo & Euphorbiaceae & 7 & 0,48 & 4,27 & 0,06 & 6,31 & 0 & 2,5 & 13,07 \\
\hline & v & Combretum leprosum Mart. & Mofumbo & Combretaceae & 5 & 0,34 & 3,05 & 0,04 & 3,6 & 0 & 1,63 & 8,28 \\
\hline & $\mathrm{s}$ & Cordia salzmanni D.C. & Maria preta & Boraginaceae & 1 & 0,07 & 0,61 & 0,01 & 0,9 & 0 & 6,65 & 8,16 \\
\hline & j & Commiphora leptophloeos (Mart) J.B. Gillett & Imburana & Burceraceae & 3 & 0,21 & 1,83 & 0,03 & 2,7 & 0 & 1,61 & 6,14 \\
\hline & 0 & Mimosa sp. & J urema morosa & Mimosaceae & 4 & 0,28 & 2,44 & 0,03 & 2,7 & 0 & 0,44 & 5,59 \\
\hline & ah & $\begin{array}{l}\text { Pilosocereus gounellei (A. Weber ex K. } \\
\text { Schum.) Byles \& Rowley }\end{array}$ & Xique xique & Cactaceae & 2 & 0,14 & 1,22 & 0,02 & 1,8 & 0 & 1,87 & 4,9 \\
\hline & $\mathrm{h}$ & Cnidoscolus phyllacanthus Pax E.K. Hoffm. & Faveleira & Euphorbiaceae & 1 & 0,07 & 0,61 & 0,01 & 0,9 & 0 & 1,87 & 3,39 \\
\hline & $n$ & Piptadenia stipulacea (Benth.) Ducke & J urema branca & Mimosaceae & 1 & 0,07 & 0,61 & 0,01 & 0,9 & 0 & 0,05 & 1,56 \\
\hline & & Total & & 2 & 164 & 11,31 & 100 & 1 & 100 & 0,05 & 100 & 300 \\
\hline \multirow{10}{*}{11} & t & Croton hemiargyreus Mull.Arg. & Marmeleiro & Euphorbiaceae & 102 & 22,94 & 63,75 & 0,44 & 44,05 & 0,03 & 23,14 & $\overline{130,94}$ \\
\hline & e & Caesalpinia pyramidalis Tul. & Catingueira & Leguminosae & 29 & 6,52 & 18,13 & 0,25 & 25 & 0,05 & 33,38 & 76,5 \\
\hline & $p$ & Mimosa hostilis Benth. & J urema preta & Mimosaceae & 12 & 2,7 & 7,5 & 0,13 & 13,1 & 0,04 & 30,48 & 51,08 \\
\hline & $\mathrm{ac}$ & Aspidosperma pyrifolium Mart. & Pereiro & Apocynaceae & 6 & 1,35 & 3,75 & 0,05 & 4,76 & 0,01 & 3,63 & 12,14 \\
\hline & v & Combretum leprosum Mart. & Mofumbo & Combretaceae & 4 & 0,9 & 2,5 & 0,05 & 4,76 & 0 & 1,89 & 9,15 \\
\hline & $\mathrm{n}$ & Piptadenia stipulacea (Benth.) Ducke & J urema branca & Mimosaceae & 2 & 0,45 & 1,25 & 0,02 & 2,38 & 0,01 & 5,5 & 9,13 \\
\hline & $x$ & Bauhinia cheilantha (Bong.) Steud. & Mororo & Caesalpinaceae & 2 & 0,45 & 1,25 & 0,02 & 2,38 & 0 & 0,59 & 4,22 \\
\hline & ah & $\begin{array}{l}\text { Pilosocereus gounellei (A. Weber ex K. } \\
\text { Schum.) Byles \& Rowley }\end{array}$ & Xique xique & Cactaceae & 2 & 0,45 & 1,25 & 0,02 & 2,38 & 0 & 0 & 3,63 \\
\hline & a & Anadenanthera macrocarpa (Benth.) Brenan & Angico vermelho & Leguminosae & 1 & 0,22 & 0,63 & 0,01 & 1,19 & 0 & 1,39 & 3,21 \\
\hline & & Total & & 9 & 160 & 35,99 & 100 & 1 & 100 & 0,14 & 100 & 300 \\
\hline \multirow{7}{*}{12} & $\mathrm{ac}$ & Aspidosperma pyrifolium Mart. & Pereiro & Apocynaceae & 82 & 5,28 & 51,25 & 0,45 & 45 & 0,04 & 72,74 & 168,99 \\
\hline & $p$ & Mimosa hostilis Benth. & J urema preta & Mimosaceae & 59 & 3,8 & 36,88 & 0,38 & 37,5 & 0,01 & 21,61 & 95,99 \\
\hline & $\mathrm{ad}$ & J atropha mollissima (Pohl.) Baill & Pinhão bravo & Euphorbiaceae & 10 & 0,64 & 6,25 & 0,1 & 10 & 0 & 3,97 & 20,22 \\
\hline & $\mathrm{t}$ & róton hemiargyreus Mull.Arg. & Marmeleiro & Euphorbiaceae & 7 & 0,45 & 4,38 & 0,05 & 5 & 0 & 1,35 & 10,72 \\
\hline & e & Caesalpinia pyramidalis Tul. & Catingueira & Leguminosae & 1 & 0,06 & 0,63 & 0,01 & 1,25 & 0 & 0,27 & 2,14 \\
\hline & s & Cordia salzmanni D.C. & Maria preta & Boraginaceae & 1 & 0,06 & 0,63 & 0,01 & 1,25 & 0 & 0,06 & 1,94 \\
\hline & & Total & & 6 & 160 & 10,3 & 100 & 1 & 100 & 0,05 & 100 & 300 \\
\hline \multirow{11}{*}{13} & e & Caesalpinia pyramidalis Tul. & Catingueira & Leguminosae & 55 & 14,48 & 34,38 & 0,25 & 25 & 0,04 & 34,87 & 94,25 \\
\hline & $\mathrm{t}$ & Croton hemiargyreus Mull.Arg. & Marmeleiro & Euphorbiaceae & 40 & 10,53 & 25 & 0,24 & 24,04 & 0,01 & 7,77 & 56,8 \\
\hline & $\mathrm{ac}$ & Aspidosperma pyrifolium Mart. & Pereiro & Apocynaceae & 24 & 6,32 & 15 & 0,17 & 17,31 & 0,03 & 23,89 & 56,19 \\
\hline & $p$ & Mimosa hostilis Benth. & J urema preta & Mimosaceae & 16 & 4,21 & 10 & 0,13 & 12,5 & 0,02 & 19 & 41,5 \\
\hline & $\mathrm{ad}$ & J atropha mollissima (Pohl.) Baill & Pinhão bravo & Euphorbiaceae & 14 & 3,69 & 8,75 & 0,12 & 11,54 & 0,01 & 9,71 & 30 \\
\hline & 0 & Mimosa sp. & J urema morosa & Mimosaceae & 4 & 1,05 & 2,5 & 0,04 & 3,85 & 0 & 2,42 & 8,76 \\
\hline & $n$ & Piptadenia stipulacea (Benth.) Ducke & J urema branca & Mimosaceae & 3 & 0,79 & 1,88 & 0,02 & 1,92 & 0 & 1,66 & 5,45 \\
\hline & k & Amburana cearensis (Fr. All.) A.C. Smith & Imburana de cheiro & Fabaceae & 2 & 0,53 & 1,25 & 0,02 & 1,92 & 0 & 0,23 & 3,4 \\
\hline & $\mathrm{h}$ & Cnidoscolus phyllacanthus Pax E.K. Hoffm. & Faveleira & Euphorbiaceae & 1 & 0,26 & 0,63 & 0,01 & 0,96 & 0 & 0,35 & 1,93 \\
\hline & v & Combretum leprosum Mart. & Mofumbo & Combretaceae & 1 & 0,26 & 0,63 & 0,01 & 0,96 & 0 & 0,12 & 1,7 \\
\hline & & Total & & 0 & 160 & 42,14 & 100 & 1 & 100 & 0,12 & 100 & 300 \\
\hline \multirow{13}{*}{14} & t & Croton hemiargyreus Mull.Arg. & Marmeleiro & Euphorbiaceae & 69 & 9,89 & 43,13 & 0,32 & 32,41 & 0,02 & 20,17 & 95,71 \\
\hline & e & Caesalpinia pyramidalis Tul. & Catingueira & Leguminosae & 31 & 4,44 & 19,38 & 0,21 & 21,3 & 0,03 & 26,86 & 67,53 \\
\hline & $p$ & Mimosa hostilis Benth. & J urema preta & Mimosaceae & 24 & 3,44 & 15 & 0,18 & 17,59 & 0,02 & 15,78 & 48,38 \\
\hline & $\mathrm{ac}$ & Aspidosperma pyrifolium Mart. & Pereiro & Apocynaceae & 12 & 1,72 & 7,5 & 0,1 & 10,19 & 0,01 & 15,32 & 33 \\
\hline & $\mathrm{h}$ & Cnidoscolus phyllacanthus Pax E.K. Hoffm. & Faveleira & Euphorbiaceae & 2 & 0,29 & 1,25 & 0,02 & 1,85 & 0,01 & 10,9 & 14 \\
\hline & 0 & Mimosa sp. & J urema morosa & Mimosaceae & 5 & 0,72 & 3,13 & 0,05 & 4,63 & 0 & 3,63 & 11,38 \\
\hline & ah & $\begin{array}{l}\text { Pilosocereus gounellei (A. Weber ex K. } \\
\text { Schum.) Byles \& Rowley }\end{array}$ & Xique xique & Cactaceae & 7 & 1 & 4,38 & 0,05 & 4,63 & 0 & 0 & 9 \\
\hline & $v$ & Combretum leprosum Mart. & Mofumbo & Combretaceae & 4 & 0,57 & 2,5 & 0,02 & 1,85 & 0 & 1,82 & 6,17 \\
\hline & a & Anadenanthera macrocarpa (Benth.) Brenan & Angico vermelho & Leguminosae & 2 & 0,29 & 1,25 & 0,02 & 1,85 & 0 & 2,69 & 5,79 \\
\hline & $\mathrm{ad}$ & J atropha mollissima (Pohl.) Baill & Pinhão bravo & Euphorbiaceae & 2 & 0,29 & 1,25 & 0,02 & 1,85 & 0 & 1,47 & 4,58 \\
\hline & 1 & Zziphus joazeiro Mart. & J uazeiro & Phamnaceae & 1 & 0,14 & 0,63 & 0,01 & 0,93 & 0 & 0,69 & 2,24 \\
\hline & $b$ & Astronium urundeuva Engl. & Aroeira & Anacardiaceae & 1 & 0,14 & 0,63 & 0,01 & 0,93 & 0 & 0,67 & 2,22 \\
\hline & & Total & & 2 & 160 & 22,93 & 100 & 1 & 100 & 0,1 & 100 & 300 \\
\hline
\end{tabular}


Continuação...

\begin{tabular}{|c|c|c|c|c|c|c|c|c|c|c|c|c|}
\hline Area & id & Nome científico & Nome comum & Família & $\mathrm{Ni}$ & $\mathrm{Di}$ & DR & fi & FR & $\mathrm{Ci}$ & CR & VI \\
\hline \multirow{17}{*}{15} & $d$ & $\begin{array}{l}\text { Piptadenia oblíqua (Pers) Macbr. Croton } \\
\text { argirophylloides }\end{array}$ & Catanduba & Mimosaceae & 57 & 15,03 & 35,63 & 0,24 & 23,66 & 0,06 & 45,94 & 105,2 \\
\hline & $\mathrm{t}$ & Croton hemiargyreus Mull.Arg. & Marmeleiro & Euphorbiaceae & 39 & 10,28 & 24,38 & 0,22 & 21,51 & 0,02 & 12,33 & 58,21 \\
\hline & $x$ & Bauhinia cheilantha (Bong.) Steud. & Mororo & Caesalpinaceae & 11 & 2,9 & 6,88 & 0,1 & 9,68 & 0,01 & 4,84 & 21,39 \\
\hline & $\mathrm{n}$ & Piptadenia stipulacea (Benth.) Ducke & J urema branca & Mimosaceae & 7 & 1,85 & 4,38 & 0,06 & 6,45 & 0,01 & 5,12 & 15,94 \\
\hline & ae & Croton sp. & Quebra faca & Euphorbiaceae & 7 & 1,85 & 4,38 & 0,06 & 6,45 & 0 & 3,65 & 14,48 \\
\hline & e & Caesalpinia pyramidalis Tul. & Catingueira & Caesalpinaceae & 6 & 1,58 & 3,75 & 0,04 & 4,3 & 0,01 & 5,66 & 13,71 \\
\hline & $c$ & Macfadyena érrea-cati (L.) Gentry & Bugio & Bignoniaceae & 6 & 1,58 & 3,75 & 0,04 & 4,3 & 0 & 0,85 & 8,9 \\
\hline & ac & Aspidosperma pyrifolium Mart. & Pereiro & Apocynaceae & 2 & 0,53 & 1,25 & 0,02 & 2,15 & 0 & 1,89 & 5,29 \\
\hline & 0 & Mimosa sp. & J urema morosa & Mimosaceae & 2 & 0,53 & 1,25 & 0,02 & 2,15 & 0 & 1,11 & 4,51 \\
\hline & v & Combretum leprosum Mart. & Mofumbo & Combretaceae & 2 & 0,53 & 1,25 & 0,02 & 2,15 & 0 & 0,75 & 4,15 \\
\hline & $p$ & Mimosa hostilis Benth. & J urema Preta & Mimosaceae & 1 & 0,26 & 0,63 & 0,01 & 1,08 & 0 & 1,77 & 3,47 \\
\hline & $\mathrm{h}$ & Cnidoscolus phyllacanthus Pax E.K. Hoffm. & Faveleira & Euphorbiaceae & 1 & 0,26 & 0,63 & 0,01 & 1,08 & 0 & 0,3 & 2 \\
\hline & ad & J atropha mollissima (Pohl.) Baill & Pinhão bravo & Euphorbiaceae & 1 & 0,26 & 0,63 & 0,01 & 1,08 & 0 & 0,22 & 1,92 \\
\hline & m & Caesalpinia érrea Mart. & Jucá & Caesalpinaceae & 1 & 0,26 & 0,63 & 0,01 & 1,08 & 0 & 0,15 & 1,85 \\
\hline & r & Manihot glaziovii Mull. Arg. & Maniçoba & Euphorbiaceae & 1 & 0,26 & 0,63 & 0,01 & 1,08 & 0 & 0,11 & 1,81 \\
\hline & $z$ & não determinada & não determinada & não determinada & 16 & 4,22 & 10 & 0,12 & 11,83 & 0,02 & 15,3 & 37,13 \\
\hline & & Total & & & 160 & 42,18 & 100 & 1 & 100 & 0,14 & 100 & 300 \\
\hline \multirow{5}{*}{16} & ac & Aspidosperma pyrifolium Mart. & Pereiro & Apocynaceae & 77 & 3,09 & 46,95 & 0,45 & 45,21 & 0,02 & 64,58 & 156,74 \\
\hline & $\mathrm{p}$ & Mimosa hostilis Benth. & J urema Preta & Mimosaceae & 65 & 2,61 & 39,63 & 0,36 & 35,62 & 0,01 & 28,55 & 103,8 \\
\hline & $\mathrm{ad}$ & J atropha mollissima (Pohl.) Baill & Pinhão bravo & Euphorbiaceae & 20 & 0,8 & 12,2 & 0,16 & 16,44 & 0 & 6,86 & 35,5 \\
\hline & ah & $\begin{array}{l}\text { Pilosocereus gounellei (A. Weber ex K. } \\
\text { Schum.) Byles \& Rowley }\end{array}$ & Xique xique & Cactaceae & 2 & 0,08 & 1,22 & 0,03 & 2,74 & 0 & 0 & 3,96 \\
\hline & & Total & & & 164 & 6,59 & 100 & 1 & 100 & 0,03 & 100 & 300 \\
\hline
\end{tabular}

buia caraíba Caubeira, Capparis flexuosa L. Feijão-bravo, Caesalpinia ferrea Mart. Ex Tul. Pau Ferro, Allamanda blanchetii A.DC. Pente de macaco, Ziziphus joazeiro Mart. Juazeiro, Gaya aurea St. Hil. Malva, Lantana camara L. Chumbinho.

Nos levantamentos realizados por Amorim et al. (2005) e Santana \& Souto (2006) na Estação Ecológica do Seridó, RN, Maracajá et al. (2003) em Serra do Mel, RN, Queiroz et al. (2006) e Andrade et al. (2005) no Vale do Cariri, na Paraíba, algumas espécies mais expressivas por este levantamento alternaram entre essas regiões. Aspidosperma pyrifolium, Caesalpinia pyramidalis e Croton sonderianus foram predominantes na E.E. Seridó e nos levantamentos no Vale do Cariri, na Paraíba, e em Serra do Mel apenas o Croton sonderianus apresentou alto VI. Na estação experimental do IPA, em Caruaru e Custódia, em Pernambuco, com fitofisionomias de menor similaridade com a vegetação do Seridó, Caesalpinia pyramidalis esteve entre as espécies de maior importância (Araújo, et. al., 1995; Alcoforado Filho et al., 2003).

Essas espécies, com a inclusão da Jatropha mollissima e Mimosa hostilis, têm largo espectro na caatinga, com importância condicionada pela região e pelo grau de intervenção (Araújo et al., 1995).

Uma avaliação de degradação foi abordada em Andrade et al. (2005), avaliando duas fitofisionomias com diferentes históricos de uso no município de São João do Cariri, PB. Foram encontradas 14 espécies em um fragmento de caatinga arbórea conservada mas utilizada para pastoreio de caprinos, e 6 espécies em um fragmento de caatinga degradada, com solo exposto, anteriormente utilizado para cultivo agrícola, mas abandonado há 30 anos. No município de Serra do Mel, um estudo similar identificou 14 es- pécies no fragmento preservado e 7 espécies no fragmento antropizado por pastoreio e retirada de madeira, para fins energéticos (Maracajá et al., 2003). As espécies mais frequentes nas áreas antropizadas foram: Pereiro, Catingueira, Marmeleiro, Pinhão bravo e Jurema preta (Maracajá et al., 2003; Andrade et al., 2005).

\section{Agrupamento dos fragmentos pelas variáveis de ambiente, cobertura e diversidade}

A análise de agrupamento permitiu a distinção física do ambiente dos fragmentos inventariados em dois grupos, considerando distância de ligação de 160 (Figura 4A), destacando-se o ambiente da Serra dos Quintos, com relevo forte ondulado a montanhoso, e solos litólicos eutróficos e distróficos, sob os fragmentos 7, 8 e 15 e, com menor similaridade, a área sob o fragmento 9; o outro ambiente incluiu as áreas com relevo plano a suave ondulado, com diferenças aproximadas de $200 \mathrm{~m}$ de altitude em relação à Serra dos Quintos, que se divide em dois subgrupos: fragmentos 10 e 14, e os fragmentos $1,2,3,4,5,6,11,12,13$ e 16 .

Os fragmentos agrupados pelas variáveis de cobertura (DT, B, H, H_DP, IAF), se dividiram em dois grandes grupos para distância de ligação de 2,5 (Figura 4B), isto é, nos fragmentos $1,7,8,9,11,13,14$ e 15, em melhor estado de conservação por esses parâmetros, e outro grupo, com os fragmentos $2,3,4,5,6,10,12$ e 16, com valores mais baixos de cobertura.

O fragmento 2, sobre neossolos, e os fragmentos 4 e 5, sobre luvissolos não degradados, apresentam características de regeneração natural, com baixa a média área basal porém com denso sub-bosque. O maior estágio de degradação ocorre nos fragmentos 3,12 e 16, sobre luvissolos crômicos vér- 
A.

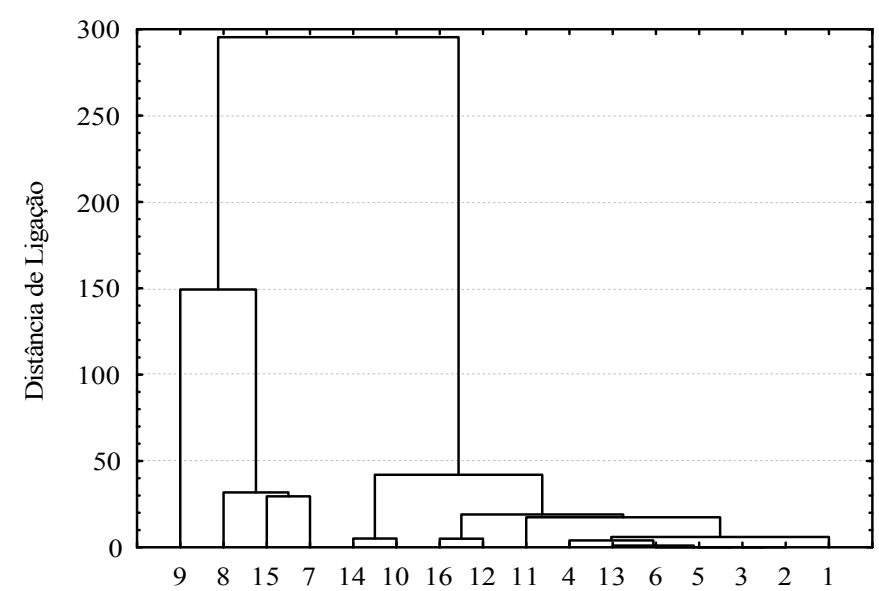

C.

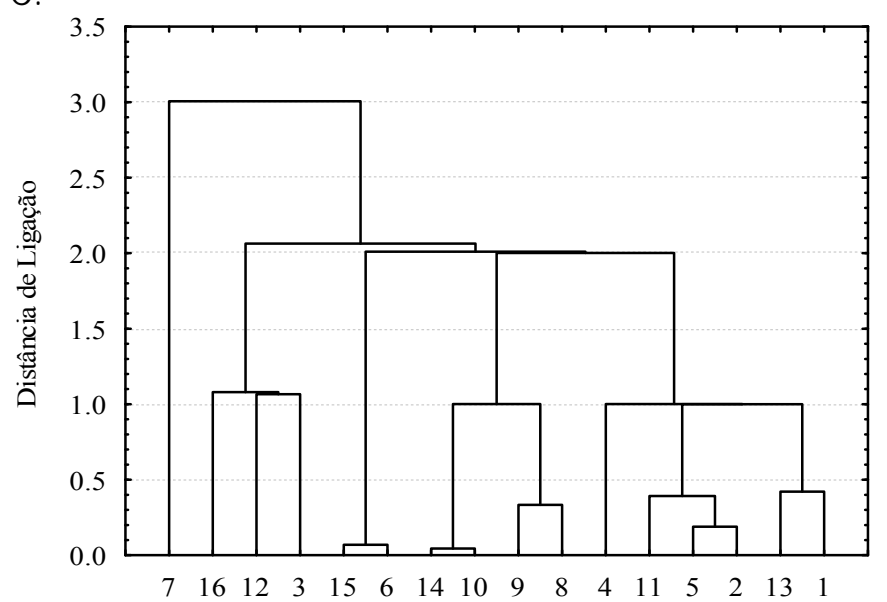

B.

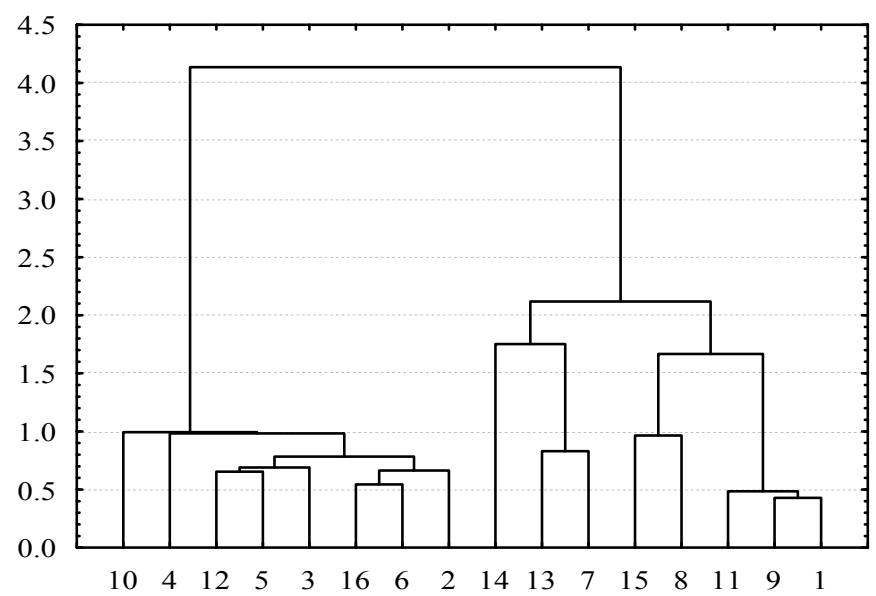

D.

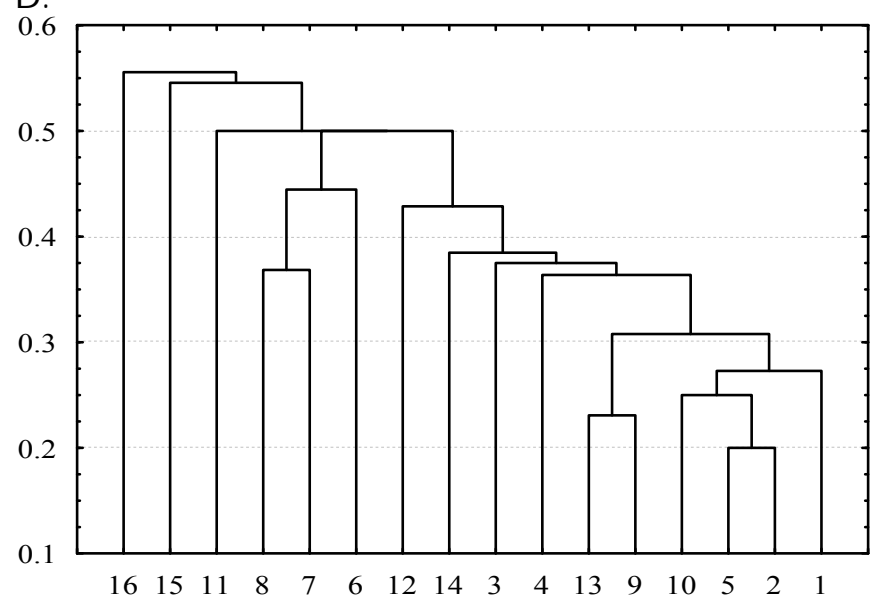

Figura 4. Dendogramas com (A) variáveis de ambiente: solo, altitude $(\mathrm{m})$, declividade $\left({ }^{\circ}\right)$, aspecto $\left(0^{\circ}-360^{\circ}\right)$; $(\mathrm{B})$ variáveis de cobertura: densidade de plantas $/ \mathrm{m}^{2}(\mathrm{DT})$, área basal $\mathrm{B}\left(\mathrm{m}^{2} / \mathrm{ha}\right)$, altura média $\mathrm{H}(\mathrm{m})$, desvio padrão da altura (H_DP), índice de área foliar (IAF); (C) variáveis de diversidade: número de espécies (NE), índice de Shannon ( $\mathrm{H}^{\prime}$ ) e de Dominância de Simpson (C); (D) coeficiente de similaridade de Jaccard entre fragmentos (Matriz de Distancia: 1 - Jaccard)

ticos em relevo plano e suave ondulado; nessas áreas se observou a erosão em sulcos, vossorocas, raras ocorrências de vegetação herbácea e de regeneração arbustivo-arborea, com predominância de solo exposto.

Esclarece-se, no grupo com maiores valores de cobertura, que o fragmento 1 é manejado para exploração de lenha em ciclos de corte de 13 a 15 anos, sobre luvissolos, com área basal elevada, favorecendo espécies pioneiras, e o fragmento 9 , sobre planossolos, se mantém sem interferência antrópica, há aproximadamente 30 anos.

Nos agrupamentos com as variáveis de diversidade, NE, Hdiver e C (Figura 4C), para a distância de ligação de 1,5 , os fragmentos 3,12 e 16 , formam o grupo de menor diversidade, o fragmento 7, o de maior diversidade, fragmentos 6 e 15 com alta diversidade, fragmentos 8, 9, 10 e 14 de média diversidade e os fragmentos $1,2,4,5,11$ e 13 de baixa diversidade. $O$ fragmento 1 tem baixa diversidade mas área basal elevada, característica de fragmentos explorados.

O fragmento 11, com 9 espécies, foi incluído no grupo de baixa diversidade devido à alta densidade do Croton hemiargyreus Mull.Arg (marmeleiro), que resultou em alta dominân- cia, assim como o fragmento 8, considerado de média diversidade em virtude da alta densidade do marmeleiro.

Por fim, o fragmento 6, em área de mineração, com baixa densidade e área basal, tem alta diversidade, com possível causa da ocorrência de cortes por clareiras, não seletivos, que resultaram na baixa densidade de indivíduos na área.

$\mathrm{O}$ agrupamento pelo índice de similaridade de Jaccard para a florística entre fragmentos foi representado na Figura 4D. Os fragmentos com florísticas menos similares no conjunto, foram 15 (entre os mais conservados) e 16 (entre os mais degradados). Maiores similaridades ocorreram entre os fragmentos 2, 5, 10, 1, 9 e 13 .

\section{Associação do ambiente com variáveis de cobertura e diversidade dos fragmentos}

Apresentam-se, na Tabela 2, correlações intra e inter grupos de variáveis; baixas correlações intra-grupos não ocorreram para algumas variáveis, em razão da multicolinearidade, optando-se pelo produto de variáveis com função similar, resultando nas seguintes variáveis: DTxB e NExHdiver. Altitude e declividade, embora com alta correlação entre si, não foram agrupadas por serem descritores conceitualmente in- 
Tabela 2. Matriz de correlação intra e inter grupos de variáveis ambientais* x cobertura e diversidade para os 16 fragmentos amostrados

\begin{tabular}{|c|c|c|c|c|c|c|c|c|c|c|c|}
\hline & Alt & Asp & Decl & 5 & DT & B & $\mathrm{H}$ & $H_{-} d p$ & IAF & $\mathrm{NE}$ & Hdiver \\
\hline Asp & 0,81 & & - & & - & - & - & - & - & - & - \\
\hline Decl & 0,94 & 0,80 & - & - & - & - & - & - & - & - & - \\
\hline $\mathrm{S}$ & 0,17 & $-0,03$ & 0,24 & - & - & - & - & - & - & - & - \\
\hline DT & 0,69 & 0,69 & 0,66 & $-0,35$ & - & - & - & - & - & - & - \\
\hline$B$ & 0,54 & 0,61 & 0,52 & $-0,36$ & 0,89 & - & - & - & - & - & - \\
\hline $\mathrm{H}$ & 0,43 & 0,45 & 0,43 & $-0,39$ & 0,67 & 0,84 & - & - & - & - & - \\
\hline$H_{-} d p$ & 0,75 & 0,67 & 0,74 & 0 & 0,70 & 0,73 & 0,76 & - & - & - & - \\
\hline$\overline{\mathrm{IAF}}$ & 0,83 & 0,7 & 0,83 & $-0,12$ & 0,89 & 0,77 & 0,67 & 0,80 & - & - & - \\
\hline $\mathrm{NE}$ & 0,7 & 0,66 & 0,57 & $-0,08$ & 0,55 & 0,47 & 0,51 & 0,65 & 0,63 & - & - \\
\hline Hdiver & 0,69 & 0,5 & 0,56 & 0,1 & 0,40 & 0,19 & 0,19 & 0,51 & 0,54 & 0,87 & - \\
\hline C & $-0,53$ & $-0,25$ & $-0,41$ & $-0,23$ & $-0,16$ & 0,07 & 0,09 & $-0,29$ & $-0,38$ & $-0,64$ & $-0,92$ \\
\hline
\end{tabular}

dependentes. Obteve-se, na análise de correlação canônica, alta correlação entre variáveis canônicas, $\mathrm{R}=0,938$, significativa a $10 \%$ de probabilidade pelo teste Lambda de Wilks, $\mathrm{c}^{2}(24$ g.1.) $=33,38 ; \mathrm{p}=0,096$. A amostra, de tamanho reduzido (16) não está sujeita a bias pelo teste de significância aproximativo, em razão da alta correlação encontrada (Lee, 2007).

As variâncias extraídas e suas redundâncias para cada variável canônica, para ambos os grupos de variáveis descritoras, são mostradas na Tabela 3.

Tabela 3. Variâncias extraídas por variável canônica de cada grupo de variáveis (de ambiente, de cobertura e diversidade) e suas respectivas redundâncias

\begin{tabular}{|c|c|c|c|c|c|}
\hline \multirow{2}{*}{ Autovetor } & \multicolumn{2}{|c|}{ Variáveis do ambiente (a) } & \multirow{2}{*}{ Autovetor } & \multicolumn{2}{|c|}{$\begin{array}{l}\text { Variáveis de cobertura e } \\
\text { diversidade (cd) }\end{array}$} \\
\hline & Var & Redun & & Var & Redun \\
\hline U1 & 0,6402 & 0,5643 & V1 & 0,5747 & 0,5066 \\
\hline U2 & 0,2042 & 0,1108 & V2 & 0,0315 & 0,0171 \\
\hline U3 & 0,0623 & 0,0241 & V3 & 0,0917 & 0,0355 \\
\hline U4 & 0,0931 & 0,0095 & V4 & 0,2131 & 0,0219 \\
\hline
\end{tabular}

Na maximização da correlação, o primeiro par de variáveis canônicas (U1, V1) concentrou a maior parte da variação dos dados, com $64 \%$ da variância para as variáveis do ambiente e $57 \%$ para as variáveis de cobertura e diversidade, sendo os demais pares desconsiderados; as combinações lineares de U1, V1, Eqs. 1 e 2, com as respectivas cargas, aplicadas às variáveis normalizadas, são:

$$
\begin{aligned}
& \mathrm{U} 1=-0.563266 \text {.Altitude }-0.174639 \text {. Aspecto - } \\
& \text { 0.328296.Declividade }+ \text { 0.235920.Solo } \\
& \begin{array}{c}
\mathrm{V} 1=-0.093591 . \mathrm{DT} \_\mathrm{B}+0.426755 . \mathrm{H}-0.364828 . \mathrm{H} \_\mathrm{dp}- \\
\text { 0.593345.IAF }-0.580876 . \mathrm{NE} \text { Hdiver }-0.324778 . \mathrm{C}
\end{array}
\end{aligned}
$$

Por meio das cargas das equações de U1 e V1 e suas respectivas correlações com as variáveis de entrada (Tabela 4), constata-se que U1 é maior para altitudes, azimutes e declividades menores; apenas a variável solo apresentou baixa correlação com U1; analogamente, V1 é maior para menores valores de densidade de indivíduos combinada com a área basal,
Tabela 4. Correlação entre variáveis de entrada e os autovetores U1 e V1

\begin{tabular}{ccc}
\hline & U1 & V1 \\
Alt & $-0,9592$ & - \\
Asp & $-0,8840$ & - \\
Decl & $-0,9270$ & - \\
S & 0,0041 & - \\
DT_B & - & $-0,8264$ \\
H & - & $-0,5593$ \\
Hdp & - & $-0,8478$ \\
IAF & - & $-0,9149$ \\
NE_Hdiver & - & $-0,8081$ \\
C & - & 0,4934 \\
\hline
\end{tabular}

quanto menor for a dispersão da altura, quanto menor for a área foliar e o número de espécies combinado com a diversidade, considerando-se as maiores correlações.

Pela dispersão entre U1 e V1, com correlação canônica de 0,88 (Figura 5), fragmentos com maior cobertura e diversidade estarão posicionados na região inferior esquerda, se associados com locais mais altos, maior declive, de menor aptidão para o uso da terra, e com maiores azimutes; inversamente, na extremidade da região superior direita do gráfico estarão os fragmentos mais degradados nos locais mais aptos, o que

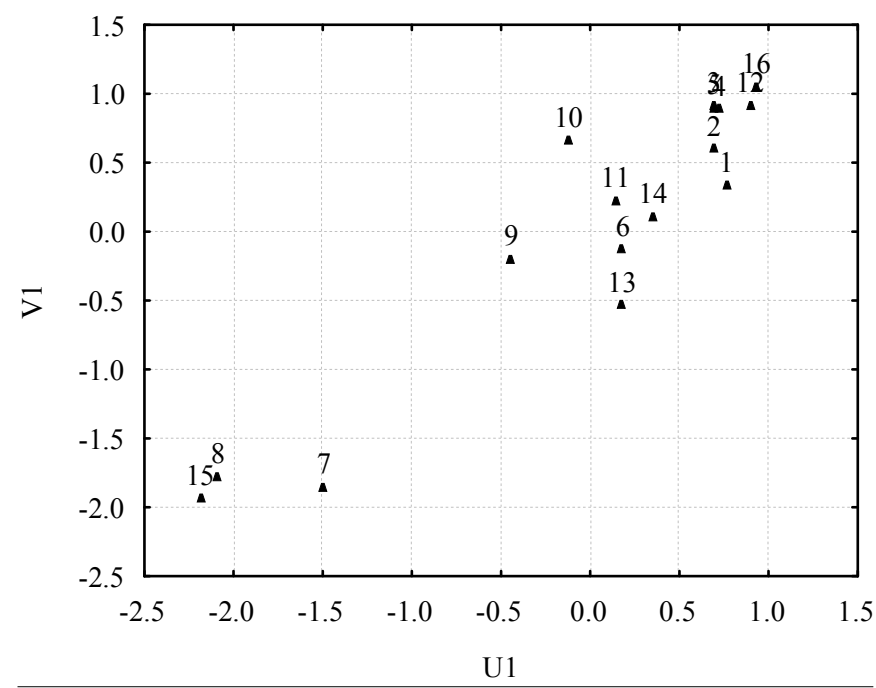

Figura 5. Dispersão de U 1 com V1 para os 16 fragmentos arbustivo-arbóreos da Caatinga do Seridó 
pode ser constatado pelos grupos de fragmentos 15,8 e 7 em uma extremidade e fragmentos 3, 12 e 16 na outra.

\section{Associação entre espécies e fragmentos}

A análise de correspondência, realizada com frequências das 32 espécies amostradas nos 16 fragmentos (incluem-se as não identificadas), gerou uma inércia total $=1,93$ com estatística $\mathrm{c}^{2}=6726,9$, g.1. $=465$ e $\mathrm{p}=0,0000$, para as 15 dimensões; as duas primeiras dimensões utilizadas para o ordenamento representam $53 \%$ da inércia total, com autovalores de 0,58 para a dimensão 1 e 0,44 para a dimensão 2 (Figura 6A). Verifica-se tendência à especificidade de um grupo de espécies nos fragmentos da Serra dos Quintos $(7,8,15)$ : Catanduba (d), Quebra faca (ae), Jucá (m), z (grupo não identificado), Umbuzeiro (af), Imburana (j), Angico vermelho (a), Jurema branca (n), Pau ferro (aa), Marmeleiro branco (u), Velame (ag), Maniçoba (r), Bugi (c), Mororó (x), Jurema morosa (o), Aroei-

A.

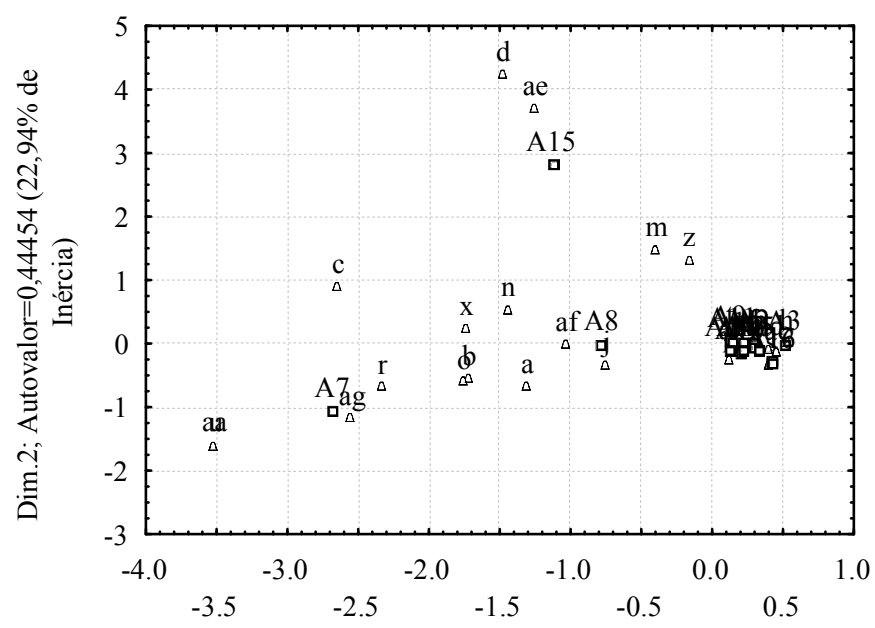

Dim.1; Autovalor $=0,58174$ (30,03\% de Inércia)

B.

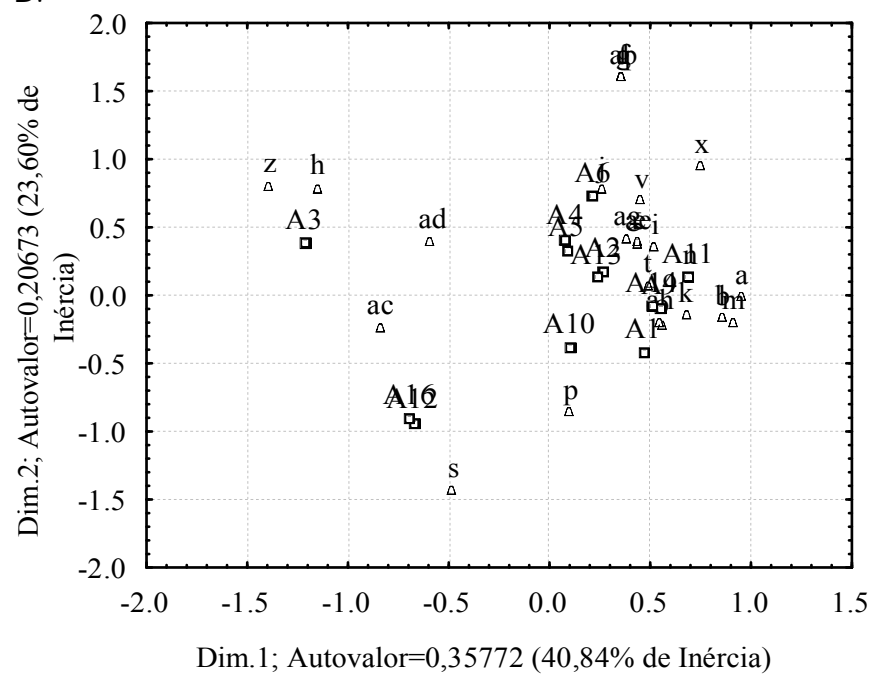

Figura 6. (A) Espécies (letras) e fragmentos entre os dois primeiros eixos (Dimensão 1 e Dimensão 2), resultantes da análise de correspondência; e (B) Espécies (letras) e fragmentos, entre os dois primeiros eixos (Dimensão $1 \mathrm{e}$ Dimensão 2), resultantes da análise de correspondência, após a exclusão dos fragmentos 7,8 e 15 ra (b), estando as outras espécies agrupadas em uma nuvem de pontos com as demais áreas.

A ocorrência quase específica das referidas espécies nesses fragmentos se relaciona, provavelmente, com a dificuldade de exploração dos locais. Pode-se levantar a suspeita de microclima pelo gradiente de altitude e orografia, mas se registraram ocorrências dessas mesmas espécies em outros levantamentos na caatinga (Tavares et al., 1969b; 1975; Alcoforado Filho et al., 2003; Maracajá et al., 2003; Lacerda et al., 2005; Santana \& Souto, 2006).

Ao se eliminar, da análise, os fragmentos 7,8 e 15 se visualiza, na Figura 6B, a associação entre espécies e fragmentos da nuvem de pontos da Figura 6A; a análise de correspondência entre 26 espécies amostradas e 13 fragmentos gerou uma inércia total $=0,87$ com estatística $\mathrm{c}^{2}=2585,5$, g.l. $=300$ e p $=0,0000$, para as 12 dimensões; as duas primeiras dimensões representam $53 \%$ da inércia total, com autovalores de 0,35 para a dimensão 1 e 0,21 para a dimensão 2 ; nota-se, na Figura 6B, o distanciamento dos fragmentos 3, 12 e 16 em relação às outras áreas. As espécies com tendência a especificidade nessas áreas, são: Faveleira (h), Pereiro (ac) e Pinhão bravo (ad). Maria preta (s) foi uma espécie de baixa ocorrência, amostrada nas áreas 10 e 12 .

No fragmento 6, com alta diversidade, foram amostradas quatro espécies de baixa ocorrência: Pente de macaco (ab), Caubeira (f), Chumbinho (g) e Malva (q), e no fragmento 9, o Feijão-bravo (i).

Pela análise de VI das espécies mais expressivas, a Jurema preta (p), mais próxima dos fragmentos 1 e 10 , obteve maior VI nesses fragmentos e $2^{\circ}$ maior VI nos fragmentos 9,12 e 16; foi a $3^{\mathrm{a}}$ espécie mais importante nos fragmentos 14 e 7 , devido a uma gleba regenerada na base da serra de um antigo corte raso, resultando na alta frequência desta espécie; a Jurema preta se destaca em fragmentos degradados e intermediários, mesmo sofrendo pressão para utilização de lenha, tratando-se de uma espécie de fácil proliferação na caatinga do Seridó.

O marmeleiro $(\mathrm{t})$, no centro da nuvem de pontos da Figura $6 \mathrm{~B}$, não se destacou nos fragmentos 3, 12 e 16; nos demais fragmentos, foi a $1^{\mathrm{a}}, 2^{\mathrm{a}}$ ou $3^{\mathrm{a}}$ espécie mais importante, excetuando-se o fragmento 7; o Marmeleiro mostrou-se sensível aos ambientes degradados avaliados, em contraposição com a informação de que é uma espécie colonizadora de áreas antropizadas, sem importância para lenha e com baixa digestibilidade para caprinos (Hardesly et al., 1988; Pereira et al., 1989; ,2001).

O Pereiro (ac) obteve o maior valor de importância apenas nos fragmentos 3,12 e 16 e $2^{\circ}$ maior VI na fragmento 2 , destacando-se como espécie adaptada a ambientes degradados por este levantamento. Andrade et al. (2005) verificaram que o Pereiro esteve presente tanto em locais conservados como alterados mas o valor de importância foi maior em locais alterados.

A Catingueira (e) obteve relativa expressão nos fragmentos com estágio de conservação intermediário, ocupando a primeira posição nos fragmentos em regeneração (4 e 5), no fragmento com alta diversidade e baixa densidade (6), e nos fragmentos 13 e 14. Em estudos realizados por Andrade et al. 
(2005) esta espécie apresentou maior densidade em área mais conservada, por ser muito explorada, em virtude do seu potencial para lenha, além de palatável para caprinos.

O Pinhão bravo (ad), embora não tenha ocupado as primeiras posições em VI, obteve relativa significância em fragmentos com maior grau de degradação e baixa importância em fragmentos mais conservados.

Pelos resultados das análises florística, fitossociológica e multivariada (agrupamento, correlação canônica, correspondência), verificou-se grande variação no número de espécies e na fitofisionomia de fragmentos relativamente próximos $(<30 \mathrm{~km})$. A estabilidade do número de espécies intra fragmentos ocorreu aproximandamente aos $400 \mathrm{~m}$, em condições climáticas homogêneas e pouca variabilidade edáfica, sendo a variação topográfica (altitude, declividade e aspecto) indicadora do grau de conservação de fragmentos. Esta constatação se deve aos descritores do ambiente, cobertura e diversidade, que indicaram uma relação direta entre conservação dos fragmentos e a baixa aptidão do ambiente para ações antrópicas.

Desta forma áreas mais vulneráveis suportam fragmentos em melhor estado de conservação. Mas mesmo a Serra dos Quintos, sem aptidão agropecuária, sofre degradação por atividades de mineração, desmatamentos na sua base e pastoreio de bovinos e caprinos. Considerando que a rica e diversificada biota da Caatinga está protegida de forma deficiente: somente 11 reservas $(<1 \%)$ são áreas de proteção integral (Leal et al., 2004), esta seria uma importante área para transformar em Unidade de Conservação (UC).

Em contraposto, fragmentos mais degradados ocorrem em áreas mais aptas, algumas em processo de desertificação pela perda do banco de sementes, do horizonte orgânico, ausência de regeneração natural, predominância de árvores adultas pioneiras e evidências de processos erosivos.

Espécies pioneiras, como a Jurema preta, Pereiro e Pinhão bravo, se destacaram no levantamento indicando a instabilidade ecológica da maioria dos fragmentos constatando-se, também, espécies preferenciais aos ambientes mais degradados; em contraposição, algumas espécies de baixa ocorrência se mostraram sensíveis a antropização, registradas apenas nos fragmentos mais conservados.

\section{CONCLUSÕES}

1. A pressão antrópica, pretérita e atual, mostra-se como causa potencial do processo de degradação do bioma caatinga no núcleo de desertificação do Seridó.

2. Algumas espécies se mostraram preferenciais nos estados de degradação ou conservação, devendo ser confirmado por outros levantamentos.

3. Para as áreas mais degradadas, mesmo abandonadas após uso agrícola, são constatados processos de desertificação, com grande dificuldade de regeneração de espécies.

4. A Serra dos Quintos abriga uma vegetação remanescente mais próxima da caatinga potencial, distinta dos demais fragmentos, e tem uma flora mais rica que a Estação Ecológica do Seridó, sendo recomendada para demarcação de uma nova Unidade de Conservação (UC).

\section{AGRADECIMENTOS}

Os autores agradecem ao CNPq, pelo apoio; à Dra. Rita de Cássia, do Instituto de Pesquisa Agropecuária, PE, pela identificação do material botânico; aos estagiários: Ana L. da Silva, Eudmar da S. A. e Ricardo A. Irmão, pelo auxílio nos trabalhos de campo, e ao Maurílio Fernandes e Adair J. Regazzi, pelas sugestões encaminhadas.

\section{LITERATURA CITADA}

Alcoforado Filho, F. G.; Sampaio, E. V. S. B.; Rodal, M. J. N. Florística e fitossociologia de um remanescente de vegetação caducifólia espinhosa em Caruaru, Pernambuco. Acta Botânica Brasílica, v.17, n.2, p.287-303, 2003.

Alves, L. I. F.; Silva, M. M. P.; Vasconcelos, K. J. C. Visão de comunidades rurais em Juazeirinho - $\mathrm{PB}$ referente à extinção da biodiversidade da caatinga. Caatinga, v.22, n.1, p.180186, 2009.

Amorim, I. L. B.; Sampaio, E. V. S.; Araújo, E. L. Flora e estrutura da vegetação arbustivo-arbórea de uma área de caatinga do Seridó, RN, Brasil. Acta Botânica Brasílica, v.19, n.3, p.615623, 2005.

Andrade, L. A.; Leite, I. M.; Tiburtino, U.; Brabosa, M. R. Análise da cobertura de duas fitofisionomias de caatinga,com diferentes históricos de uso, no município de São João do Cariri, Estado da Paraíba. Cerne, v.11, n.3, p.253-262, 2005.

Andrade-Lima, D. The caatinga dominium. Revista Brasileira Botânica, v.4, n.2, p.149-153, 1981.

Araújo, E. L.; Sampaio, E. V. S. B.; Rodal, M. J. N. Composição florística e fitossociologia de três áreas de caatinga de Pernambuco. Revista Brasileira de Biologia, v.55, n.4, p.595-607, 1995.

Barbosa, M. R. V.; Lima, I. B.; Lima, J. R.; Cunha, J. P.; Agra, M. F.; Thomas, W. W. Vegetação e flora no Cariri Paraibano. Oecologia Brasiliensis, v.11, n.3, p.313-322, 2007.

Brzeziecki, B.; Kienast, F.; Wildi, O. A simulated map of the potential natural forest vegetation of Switzerland. Journal of Vegetation Science, v.4, p.499-508, 1993.

Camacho, R. G. V. Estudo fitofisiográfico da caatinga do Seridó - Estação Ecológica do Seridó, RN. São Paulo: USP, 2001. 130p. Dissertação Mestrado

Costa, R. C.; Araujo, F. S.; Lima-Verde, L. W. Flora and life-form spectrum in an área of decíduous thorn woodland (caatinga) in northeastern, Brazil. Journal of Arid Environments, v.68, p.237-247, 2007.

Costa, T. C. C.; Accioly, L. J. O.; Oliveira, M. A. J.; Burgos, N.; Silva, F. H. B. B. Phytomass mapping of the "Seridó caatinga" vegetation by the plant area and the normalized difference vegetation indexes. Scientia Agrícola, v.59, p.707-715, 2002.

Costa, T. C. C.; Souza Neto, N. C.; Oliveira, M. A. J.; Accioly, L. J. O. Estimativa da diversidade florística da caatinga por meio da análise multicriterial. In: Simpósio Brasileiro de Sensoriamento Remoto (SBSR), 11, 2003, Belo Horizonte. Anais... São José dos Campos: INPE, 2003. CD Rom. 
Cottam, G.; Curtis, J. T. The use of distance in phytossociological sampling. Ecology, v.37, p.451-460, 1956.

Farias, R. R. S.; Castro, A. A. J. F. Fitossociologia de trechos da vegetação do complexo de Campo Maior, Campo Maior, PI, Brasil. Acta Botânica Brasílica, v.18, n.4, p.2-13, 2004.

Gomes, A. P. S.; Rodal, M. J. N.; Melo, A. L. Florística e fitogeografia da vegetação arbustiva subcaducifolia da Chapada de São José, Buíque, PE, Brasil. Acta Botânica Brasílica, v.20, n.1, p.37-48, 2006.

Hardesty, L. H.; Box, T. W.; Mlaechek, J. C. Season of cutting affects biomass production by browse species of the brazilian caatinga. Journal of Range Management, v.41, n.6, p.477480, 1988.

IBAMA - Instituto Brasileiro do Meio Ambiente e dos Recursos Naturais Renováveis. Diagnóstico florestal do Rio Grande do Norte / Plano de manejo florestal para a região do Seridó do Rio Grande do Norte. Projeto PNUD/FAO/IBAMA/BRA/ 87/ 007. Natal: Ministério do Meio Ambiente, 1993. 45p.

Johnson, R. A.; Wichern, D. W. Applied multivariate statistical analysis. 2.ed. New Jersey: Prentice-Hall, 1988. 606p.

Krebs, C. J. Ecological methodology. New York: Harper \& Row, 1989. 652p.

Lacerda, A. V.; Nordi, N.; Barbosa, F. M.; Watanabe, T. Levantamento florístico do componente arbustivo - arbóreo da vegetação ciliar na bacia do rio Taperoá, PB, Brasil. Acta Botânica Brasílica, v.19, n.3, p.647-656, 2005.

Leal, I. R.; Silva, J. M.; Tabarelli, M.; Lacher Jr.; T. E. Mudando o curso da conservação da biodiversidade na Caatinga do Nordeste do Brasil. In: Conservação internacional do Brasil (ed.). Megadiversidade, v.1, p.139-146, 2005.

Lee, H. Canonical correlation analysis using small number of samples. Communications in Statistics-Simulation and Computation, v.36, p.973-985, 2007.

Luetzelburg, P. V. Estudo botânico do Nordeste. Rio de Janeiro: Inspetoria Federal de Obras Contra as Secas, v.3, n.57, Série 1-A, p.197-250, 1923.

Magurran, A. E. Ecológica diversity and its measurement. Princeton: Pricenton University Press, 1991. 179p.

Manly, B. F. J. Multivariate statistical methods. London: Chapman \& Hall, 1994. 214p.

Maracajá, P. B.; Batista, C. H. F.; Sousa, A. H.; Vasconcelos, W. E. Levantamento florístico e fitossociológico do estrato arbustivo-arbóreo de dois ambientes na vila Santa Catarina, Serra do Mel, RN. Revista de Biologia e Ciência da Terra, v.3, n.2, p.25-32, 2003.

Martins, F. R. Estrutura de uma floresta mesófila. Campinas: UNICAMP, 1993. 246p.

Matalho, J. H. Indicadores de desertificação. Brasília: UNESCO, v.II, 2001, 126p.

Moreira, J. N.; Lira, M. A.; Santos, M. V. F.; Ferreira, M. A.; Araújo, G. G. L.; Ferreira, R. L. C.; Silva, G. C. Caracterização da vegetação de Caatinga e da dieta de novilhos no Sertão de Pernambuco. Pesquisa Agropecuária Brasileira, v.41, n.11, p.1643-1651, 2006.

Pereira, I. M.; Andrade, A. de A.; Costa, J.R.M; Dias, J. M. Regeneração natural em um remanescente de caatinga sob diferentes níveis de perturbação, no agreste paraibano. Acta Botânica Brasílica, v.15, n.3, p.413-426, 2001.
Pereira, R. M. A; Araujo Filho, J. A; Lima, R. V. Estudos fenológicos de algumas espécies lenhosas e herbáceas da caatinga. Ciências Agronômicas, v.20, n.12, p.11-20, 1989.

Queiroz, J. A.; Trovão, D. M. B. M.; Oliveira, A. B.; Oliveira, E. C. S. Análise da Estrutura fitossociológica da Serra do Monte, Boqueirão, Paraíba. Revista de Biologia e Ciências da Terra, v.6, n.2, p.251-259, 2006.

Reis, A. M. S.; Araújo, E. L.; Ferraz, E. M. N.; Moura, A. N. Inter-annual variations in the floristic and population structure of an herbaceous community of "caatinga" vegetation in Pernambuco, Brazil. Revista Brasileira de Botanica, v.29, n.3, p.497-508, 2006.

Rocha, P. L.; Queiroz, L. P.; Pirani, J. R. Plant species and habitat structure in a sand dune field in the Brazilian Caatinga: a homogeneous habitat harbouring an endemic biota. Revista Brasileira de Botanica, v.27, n.4, p.739-755, 2004.

Rodal, M. J. N. Fitossociologia da vegetação arbustivo-arbórea em quatro áreas de caatinga em Pernambuco. Campinas: UNICAMP, 1992. 224p. Tese Doutorado

Rodal, M. J. N.; Andrade, K. V. A.; Sales, M. F.; Gomes, A. P. S. Fitossociologia do componente lenhoso de um refúgio vegetacional no município de Buíque, Pernambuco. Revista Brasileira Biologia, v.58, p.517-526, 1998.

Sampaio, E. V. S. B.; Araujo, E. L.; Salcedo, I. H. J; Salcedo, I. H.; Tiessen, T. H. Regeneração da vegetação da caatinga após o corte e queima, em Serra Talhada, PE. Pesquisa Agropecuária Brasileira, v.33, n.5, p.612-632, 1998.

Santana, J. A. da S.; Souto, J. S. Diversidade e estrutura fitossociológica da caatinga na estação ecológica do Seridó, RN. Revista de Biologia e Ciência da Terra, v.6, n.2, p.232-242, 2006.

Santos, M. F. A. V. Características dos solos e da vegetação em sete áreas de Parnamirim, Pernambuco. Recife: UFRPE, 1987. 230p. Dissertação Mestrado

Santos, R. M.; Vieira, F. A.; Fagundes, M.; Nunes, Y. R. F.; Gusmão, E. Riqueza e similaridade florística de oito remanescentes florestais no norte de Minas Gerais, Brazil. Revista Árvore, v.31, n.1, p.135-144, 2007.

Seridó. Globo comunidade. Rio Grande do Norte: Rede Globo, 23 Abr. 2001.

Silva, F. H. B. B.; Burgos, N.; Accioly, L. J. O.; Costa, T. C. C.; Oliveira, M. A. J. Caracterização dos recursos naturais de um fragmento do núcleo de desertificação do Seridó, estados do Rio Grande do Norte e da Paraíba. Escala 1: 100.000. Recife: EMBRAPA, 2001, p.23-53. Boletim de Comunicações Administrativas

Silva, I. H. Correlações entre a vegetação e tipos distintos de solos do Baixio de Irecê, Bahia. Recife: UFRPE, 1991. 104p. Dissertação Mestrado

Simpson, E. H. Measurement of diversity. Nature, v.163, p.163688, 1949.

Tavares, S.; Paiva, F. A. F.; Tavares, E. J. S.; Carvalho, G. H. Inventário Florestal na Paraíba e no Rio Grande do Norte; I Estudo preliminar das matas remanescentes do Vale do Piranhas. Série: Brasil. SUDENE, Recursos Vegetais, v.4, 1975, 31p.

Tavares, S.; Paiva, F. A. F.; Tavares, E. J. S.; Carvalho, G. H.; Lima, J. L. S. Inventário florestal de Pernambuco. Estudo preliminar das matas remanescentes dos municípios de Ouricuri, Bodocó, Santa Maria da Boa Vista e Petrolina. Boletim de Recursos Naturais da SUDENE, v.8, p.149-194, 1970. 
Tavares, S.; Paiva, F. A. F.; Tavares, E. J. S.; Lima, J. L. S. Inventário florestal do Ceará. Estudo preliminar das matas remanescentes do Município de Quixadá. Boletim de Recursos Naturais da SUDENE, v.7, n.1-4, p.93-111, 1969a.

Tavares, S.; Paiva, F. A. F.; Tavares, E. J. S.; Lima, J. L. S. Inventário florestal do Ceará. II-Estudo preliminar das matas remanescentes do município de Tauá. Boletim de Recursos Naturais da SUDENE, v.12, n.2, p.5-19, 1974a.

Tavares, S.; Paiva, F. A. F.; Tavares, E. J. S.; Lima, J. L. S. Inventário florestal do Ceará. III-Estudo preliminar das matas remanescentes do município de Barbalha. Boletim de Recursos Naturais da SUDENE, v.12, n.2, p.20-46, $1974 b$.

Tavares, S.; Paiva, F. A. F.; Tavares, E. J. S.; Lima, J. L. S. Carvalho, G. H. Inventário florestal de Pernambuco. Estudo preliminar das matas remanescentes do Município de São José de Belmonte. Boletim de Recursos Naturais da SUDENE, v.7, n.1-4, p.113-139, 1969 b.
Trovão, D. M. B. M.; Fernandes, P. D.; Andrade, L. A.; Dantas Neto, J. D. Variações sazonais de aspectos fisiológicos de espécies da Caatinga. Revista Brasileira de Engenharia Agrícola e Ambiental, v.11, n.3, p.307-311, 2007.

Trovão, D. M. B. M.; Silva, S. C.; Silva, A. B.; Vieira Júnior, R. L. Estudo comparativo entre três fisionomias de caatinga no estado da Paraíba e análise do uso das espécies vegetais pelo homem nas áreas de estudo. Revista Biologia e Ciências da Terra, v.4, n.2, p.1-5, 2004.

United Nations. Agenda 21, Brasília: Senado Federal , 1994. 591p. Veloso, H. P.; Góes Filho, L. Fitogeografia brasileira, classificação fisionômica ecológica da vegetação neotropical. Projeto RADAMBRASIL, Salvador: Boletim Técnico, $1^{\text {a }}$ Série Vegetação, 1982, 80p.

White, M. A.; Asner, G. P.; Nemani, R. R.; Privette, J. L.; Running, S. W. Measuring fractional cover and leaf area index in arid ecosystems: digital camera, radiation transmittance, and laser altimetry methods. Remote Sensing of Environment, v.74, p. $45-57,2000$. 